NBER WORKING PAPER SERIES

\title{
THE VALUE OF MANDATING MATERNAL EDUCATION IN A DEVELOPING COUNTRY
}

\author{
Bahadir Dursun \\ Resul Cesur \\ Inas Rashad Kelly \\ Working Paper 23492 \\ http://www.nber.org/papers/w23492 \\ NATIONAL BUREAU OF ECONOMIC RESEARCH \\ 1050 Massachusetts Avenue \\ Cambridge, MA 02138 \\ June 2017
}

We thank Jorge M. Agüero, Dhaval M. Dave, Michael Grossman, Adalet Keskin, Naci Mocan, Prakarsh Singh, Erdal Tekin, Jennifer M. Trudeau, seminar participants at the Southern Economic Association 2016 Meeting, 2016 Development Economics Conference at Fordham University, Eastern Economic Association 2017 Meeting, Auburn University, University of Southern Mississippi, CBRT, Koc University, Sabanci University, University of South Florida, Texas A\&M University, San Antonio, and RAND for their valuable comments and suggestions. We are grateful to Şebnem Beşe Canpolat and the Demographic Statistics Department of Turkish Statistical Institute for their assistance with respect to the Population and Housing Census 2011 data. The authors thank Dr. Emel Ergün Seyit for providing insights about the collection of birth outcomes data at the Family Health Centers in Turkey. All remaining errors are our own. The views expressed herein are those of the authors and do not necessarily reflect the views of the National Bureau of Economic Research.

NBER working papers are circulated for discussion and comment purposes. They have not been peer-reviewed or been subject to the review by the NBER Board of Directors that accompanies official NBER publications.

(C) 2017 by Bahadir Dursun, Resul Cesur, and Inas Rashad Kelly. All rights reserved. Short sections of text, not to exceed two paragraphs, may be quoted without explicit permission provided that full credit, including $\odot$ notice, is given to the source. 
The Value of Mandating Maternal Education in a Developing Country

Bahadir Dursun, Resul Cesur, and Inas Rashad Kelly

NBER Working Paper No. 23492

June 2017

JEL No. I12,I21,I26,J13

\begin{abstract}
While several studies estimate the impact of maternal education on birth weight and child mortality using quasi-experimental identification strategies in developing countries, the state of the literature on the causal relationship between maternal education and child health is far from being complete:(i) the extant literature offers conflicting findings; (ii) the local average treatment effects of maternal education, induced by different types of natural experiments, on child health are not well-distinguished; and (iii) many of the existing articles are undermined by limited statistical power due to small sample sizes and/or a weak first stage. To fill the void in the literature, we examine the impact of mother's extended primary schooling on birth outcomes and child mortality using two large data sets from the Republic of Turkey. We use the 1997 education reform, which extended the duration of mandatory schooling from 5 to 8 years, to address the endogeneity of maternal education to children's outcomes. A unique feature of the schooling reform of 1997 is that, in a developing country, it arguably provides one of the most suitable empirical frameworks to identify the local average treatment effect of compulsory education among women with a low tendency to extend their schooling beyond five years of elementary school. Results show that an increase in mother's schooling improves child health at birth (such as through a reduction in the likelihood of low birth weight and premature births) and lowers child mortality. Moreover, it improves outcomes pertaining to method of birth delivery and maternal smoking. These findings survive a number of sensitivity tests. The current study provides robust evidence in favor of the argument that increasing the duration of mandatory primary education among women who have a low interest in receiving more schooling may have substantial non-pecuniary benefits in terms of the health of the offspring in developing countries.

Bahadir Dursun

Department of Economics

Louisiana State University

2326A BEC

Baton Rouge, LA 70803

odursu2@1su.edu

Resul Cesur

University of Connecticut

School of Business

2100 Hillside Road

Storrs, CT 06269

and NBER

cesur@uconn.edu

Inas Rashad Kelly

Queens College, CUNY

Economics Department

300 Powdermaker Hall

65-30 Kissena Boulevard

Flushing, NY 11367

and NBER

Inas.Kelly@qc.cuny.edu
\end{abstract}




\section{INTRODUCTION}

Exploiting different natural experiments, a number of studies have analyzed the causal effect of maternal education on child outcomes in developing countries. The literature thus far, though, has provided incomplete evidence on the impact of mother's schooling on offspring's health in terms of infant health at birth and child mortality. Although there is research showing that maternal education has a favorable impact on child health (Breierova and Duflo 2004; Chou et al. 2010; Grépin and Bharadwaj 2015; Günes 2015; Makate and Makate 2016), there is also evidence suggesting that mother's schooling has little effect on birth outcomes and infant mortality (Keats 2014; Zhang 2014). ${ }^{1}$

Aside from the non-uniformity on whether parental schooling causally impacts health outcomes of children, existing literature offers fairly limited information on specific policy implications of the local average treatment effects (LATE) of alternative education reforms among different types of populations. For instance, some natural experiments enable researchers to tease out the impact of increased educational attainment among people with a high interest in receiving more education (such as through increased school availability and/or the elimination of school fees when those who desire to attend school cannot afford it). Conversely, exogenous variation in education induced by compulsory schooling laws allows one to examine the impact of education among those with a low tendency to obtain additional years of schooling. Given that many developing nations have weakly enforced compulsory schooling laws and usually require relatively few years of education (UN 2015), separating the impact of extra schooling among individuals with a low tendency to attend school from that of increases in educational attainment of those with a greater propensity to get education may have important policy implications.

Additionally, most studies coming from developing countries are hindered by limited statistical power due to small sample sizes and/or a lack of strong instrumental variables to predict statistically and

\footnotetext{
${ }^{1}$ Research focused on affluent societies also offers conflicting evidence on whether maternal education causally impacts child health. While some studies document that maternal education improves child health (Currie and Moretti 2003; Grytten, Skau, and Sørensen 2014), a handful of others (Lindeboom, Llena-Nozal, and van der Klaauw 2009; McCrary and Royer 2011) do not find a statistically significant relationship between the two.
} 
economically significant changes in schooling. Hence, the current incomplete state of the literature on maternal education and child health warrants more research (Grossman 2015).

Using two large data sets from the Republic of Turkey, the current study examines the causal effect of mandatory maternal education on birth outcomes and child mortality by utilizing the 1997 education reform, which extended the duration of minimum years of compulsory schooling from 5 to 8 years, as the source of exogenous variation in mother's education. Our analysis exploits the fact that those born after 1986 are bound by the 1997 schooling law to acquire at least eight years of basic education. Thus, we use exposure to the reform as an instrumental variable to estimate the impact of mother's likelihood of holding at least a middle school diploma on birth outcomes and child mortality.

The 1997 compulsory schooling reform, for the most part, caused an increase in the educational attainment of girls with a relatively low interest in attending middle school because of a high degree of stigma associated with female schooling in Turkey (Dulger 2004). Although Turkey was classified as a middle-income country during the 1990s, gender inequality in education was exceptionally high, with women lagging behind men in education (Otaran et al. 2003). As we later discuss in greater detail, for a developing country, this aspect of the 1997 education reform makes it one of the rare cases where one can examine what happens when the government forces girls to obtain extra schooling at the lower tail of the educational attainment distribution.

Child health outcomes analyzed in this paper include very low birth weight (<1500 grams), low birth weight (<2500 grams), and high birth weight $(>4500$ grams); child mortality (deceased before age five); gestation; and premature birth (gestation < 37 weeks). In addition, maternal outcomes analyzed include the method of birth delivery and propensity to smoke. Results indicate that mothers who completed at least eight years of schooling are less likely to deliver babies with very low birth weight, low birth weight, and high birth weight, and they are less likely to have a child deceased before age five. Furthermore, obtaining at least a middle school degree extends gestational age and lowers the propensity of delivering premature babies. Lastly, we also find evidence suggesting that additional education, 
through exposure to the reform, increases the likelihood of a vaginal delivery and lowers maternal smoking.

This research contributes to the maternal education and child health literature in developing countries in a number of ways. First, our findings provide robust evidence in favor of the view that maternal education improves child health. Second, these results support the argument that mandated education may be instrumental in improving public health in developing countries. Thus, in addition to increasing resources for primary and secondary education in developing societies, enacting compulsory schooling laws, which require a minimum number of years of completed schooling, and enforcing them to increase educational attainment of females with a low interest in attending school may have significant benefits in terms of children's health. We also show evidence that without a sufficiently large sample, the instrumental variable estimates of the impact of the treatment variable (e.g., maternal education) on outcome measures (such as child health at birth and child mortality) may be biased when (i) only a relatively small fraction of those in the treatment group are impacted by the instrumental variable at hand, and (ii) the mean of the dependent variable is fairly small.

The rest of the article is organized as follows. The next section describes the 1997 education reform. Section III discusses the conceptual framework and reviews the relevant literature. Section IV presents the data and measures. In Section V, the econometric methodology is laid out. Section VI displays the main estimates. Section VII performs robustness checks, explores potential heterogeneity, and implements a two-sample instrumental variable estimation strategy for birth outcomes. Section VIII examines the impact of additional education on maternal behaviors. Finally, Section IX concludes.

\section{IDENTIFICATION: THE 1997 EDUCATION REFORM}

Until mid-1990s, the Turkish primary and secondary education system was comprised of three stages: elementary school (5 years), junior high school (3 years), and high school (3 years). Of these, completing the first stage (i.e., 5-year elementary school) was compulsory, and whether a child continues schooling after earning an elementary school diploma was left to the discretion of families. Non-compliance is 
subject to monetary fines in Turkey even though they are not always strictly imposed, and with the exception of books, supplies, school uniforms, and commuting costs, all public primary and secondary schools are free of charge in Turkey. ${ }^{2}$

In 1997, the Turkish Parliament increased the duration of compulsory schooling from 5 to 8 years. Known as the "eight-year uninterrupted education reform," law number 4306 required children to continue primary schooling until earning a middle school degree, which corresponds to at least 8 years of schooling (Dulger 2004). Chief motivators behind the enactment of the 1997 education reform were the efforts towards endorsing Turkey's accession to the European Union and curbing the rise of Political Islam. ${ }^{3}$ The reform became effective in the 1998-99 academic year, combining the first two stages (i.e., elementary and lower secondary) of schooling under the umbrella of Primary School (İlköğretim Okulu). The new legislation meant that children who completed fifth grade in 1998 were obliged to continue their education until they earned a middle school degree. In other words, those who started elementary school in the 1993-94 academic year were the first cohort to be impacted by the law (Dursun and Cesur 2016). Because the Turkish law allows pupils who are 72 months old by the end of the calendar year to begin elementary schooling in the corresponding academic year (Dinçer, Kaushal, and Grossman 2014), children who were born in 1987 constitute the first fully affected birth cohort. ${ }^{4}$ Note that as parents (and school administrators) can exert a considerable degree of discretion with respect to school starting age, some children can start elementary school a year earlier than their own birth cohort and vice versa (Torun 2015). Therefore, while the majority of children born in 1986 were likely to start elementary school in 1992 and not bound by the reform, some of them possibly delayed it to 1993 and were impacted by the reform. This aspect of the education system in Turkey imposes some ambiguity with respect to whether children born in 1986 were affected by the compulsory schooling reform of 1997 . Therefore, following the approach taken by Battistin et al. (2009), Cesur and Mocan (2013), Fort, Schneeweis, and Winter-

\footnotetext{
${ }^{2}$ See http://spm.ku.edu.tr/wp-content/uploads/pdf/okulterk.pdf and http://mevzuat.meb.gov.tr/html/24.html for more detail.

${ }^{3}$ See Cakir, Bozan, and Talu (2004) and Cesur and Mocan (2013) for a detailed discussion of the political developments leading to the legislation of the 1997 education reform.

${ }^{4}$ Resmi Gazete; Friday, 7 August 1992, Section 14.
} 
Ebmer (2016), and Dursun and Cesur (2016) in examining the implications of similar schooling reforms, including the current one, we exclude the 1986 birth cohort from our main analysis to get a handle around this issue. ${ }^{5}$

Importantly, the reform mainly focused on increasing educational attainment and made no curricular or compositional changes (Dulger 2004). Therefore, our identification strategy relies on the following assumption: Once the trends at the birth cohort level are accounted for, those born before 1986 should constitute an ideal comparison group for individuals who were born after 1986. This type of an instrumental variable is consistent with the fuzzy regression discontinuity design (Oreopoulos 2006; Lee and Lemieux 2010; Brunello, Fabbri, and Fort 2013; Clark and Royer 2013).

To supplement the mandate of the reform, which aimed to increase enrollment especially among females, the Ministry of Education made a number of changes, including adding new classrooms to existing schools, hiring new teachers, incorporating a bus system to carry students from rural areas to urban schools, reorganizing the geographic distribution of public schools, and providing free books and lunch to poor children (Turkish Ministry of National Education (MONE) 2001; Dulger 2004). Notably, the reform increased classroom capacity at existing schools as opposed to constructing new schools in different localities. As shown in Appendix Table 1, the total number of Primary Schools, which were established after the reform by uniting the Elementary and Middle Schools, is lower than the number of Elementary Schools prior to the enactment of the 1997 education reform. This is because the classroom capacity of urban public schools was extended at the expense of closed elementary schools in rural areas (Dulger 2004). In addition, in a number of rural areas, schools were consolidated into a single school for clusters of villages (Dulger 2004). To compensate for school closures in non-urban areas, children in villages without Primary Schools were transported by bus to the nearest available school; hence, the number of students who were bussed increased significantly shortly after the reform (Erçelebi 2000; Dulger 2004). Lastly, in central locations, the capacity of boarding schools was expanded after the reform to catch up with increased enrollment (Dulger 2004; World Bank 2005). Consequently, as shown in

\footnotetext{
${ }^{5}$ However, including the 1986 cohort in the analysis sample has no bearing on our estimates.
} 
Appendix Figure 1, trends in the percent of women holding at least a middle school degree exhibited a secular jump among women who were bound by the reform. ${ }^{6}$

Predictably, using the "eight-year uninterrupted education reform" as the source of identifying variation, a number of studies have examined the causal impact of extended primary schooling on different outcomes, including earnings, subjective well-being, religiosity, marital status, fertility, health outcomes, gender gap in educational attainment, and domestic violence (Cesur, Dursun, and Mocan 2014; Mocan 2014; Dinçer, Kaushal, and Grossman 2014; Güneş 2015, 2016; Torun 2015; Dursun and Cesur 2016; Erten and Keskin forthcoming).

Secondary school attainment could have increased after the 1997 education reform among two different types of female populations: (i) girls with a fairly low interest in receiving more education may have increased their educational attainment due to the mandate of the reform; and (ii) those with a high zeal to attend middle school could have enrolled in a school because of increased school availability and/or reduction in cost of education. ${ }^{7}$ Even before the reform, school availability was not an obstacle to enrollment in urban areas because nearly all urban localities had a middle school (according to the Ministry of National Education Yearbooks 1991-92 to 1997-98), and no student could be denied enrollment (Turkish Constitution Article 42, and Ministry of National Education Legislation). ${ }^{8}$ As we discussed above, the geographical convenience of schools did not increase due to the 1997 reform. On the contrary, schools became more concentrated after the reform and students were transported from rural areas to the nearest schools using the bussing system, and the capacity of boarding schools in central areas

\footnotetext{
${ }^{6}$ As the focus of the current study is examining the impact of maternal education on child health, we display the trends in educational attainment of women who gave birth to at least one child. However, using different data sets, a number of studies show that the 1997 compulsory schooling reform caused a significant increase in the lower secondary schooling of both men and women in all parts of the country regardless of urban versus rural residential status or of birth of children (Cesur and Mocan 2013; Mocan 2014; Torun 2015; Dursun and Cesur 2016).

${ }^{7}$ Note that the decision to attend middle school upon completing a five-year elementary school degree is made when the child is 11 years old. Hence, while in some cases the decision surrounding whether to attend middle school may be solely decided by the child, families play a major role in the schooling decision of their children. However, for ease of expression, children's propensity to attend middle school is used interchangeably (and/or jointly) with the interest of their families.

${ }^{8}$ While we acknowledge the possibility that in some cases a student might have been denied enrollment due to classroom capacity constraints, it was extremely rare and temporary even before the 1997 education reform was in effect.
} 
was expanded to compensate for school closures and accommodate increased enrollment. Therefore, investments in school capacity did not improve the convenience of attending nearby schools. However, the school bus system and boarding schools could have lowered the cost of commuting to schools for students residing in rural areas.

All in all, the 1997 education reform targeted those with a low propensity to attend middle school, especially among females (Dulger 2004; Mocan 2014). As supported by the available evidence, we argue that even for those living in rural areas, the schooling mandate played a much bigger role in increasing educational attainment. To begin with, the reform had a greater impact on female education compared to that of males (Mocan 2014; Torun 2015; Dursun and Cesur 2016). It is well known that there has been a considerably high degree of stigma attached to girls attending secondary schools in Turkey (TDHS 1998; Aytaç and Rankin 2004; Rankin and Aytaç 2006; Unicef 2007). If there is stigma pertaining to female schooling, it stands to reason that girls are less likely to continue their education upon earning a five-year elementary school diploma in the absence of mandatory schooling; thus, the enactment of a compulsory education law may have a larger impact on female schooling. Therefore, the differential positive effect of the reform on male and female schooling (in favor of women) supports the view that the compulsory nature of the reform played a key role in increasing educational attainment. To gain further insight into the reasons for why females did not pursue secondary schooling prior to the 1997 education reform, we use data from the Turkish Demographic and Health Surveys (TDHS) collected in 1998. Specifically, among those who earned at least a primary school diploma (i.e., a minimum of 5 years of schooling), TDHS 1998 asks ever married women between the ages 15 to 24 (i.e., born between 1974 and 1983) why they quit or did not attend school at all. As these women are only a few years older than the ones who were bound by the 1997 education reform, knowing why they stopped attending school after receiving five years of basic education can provide helpful information on how the 1997 education reform induced females to obtain more schooling. Results, presented in Appendix Table 2, show that a sizable 40 percent of women who dropped out of or did not go to middle school at all declared that their family did not allow them to continue their education, and roughly 20 percent reported that they did not like school or could 
not pass the exams. On the other hand, 5.5 and 5.6 percent of them attribute it to the lack of a suitable nearby educational institution and not being able to afford school expenses, respectively. Moreover, only 1.4 and 1.6 percent declared that they needed to earn money and help their families, in that order.

Therefore, we conclude that the mandate of the law was the major reason behind the jump in educational attainment due to the 1997 compulsory schooling reform while we acknowledge that we cannot fully dismiss the potential role of a reduction in the cost of attending school. This particular property of the natural experiment at hand has a major implication. That is, the LATE obtained from this policy change primarily corresponds to the impact of extended primary education among individuals with a low tendency to continue their schooling beyond five years of basic education. To the extent of our knowledge, this aspect of the "eight-year uninterrupted education reform" makes it the closest natural experiment that approximates the impact of compulsory schooling among women with a relatively low interest in receiving additional education in a developing country. All other reforms in developing countries that have been utilized in the literature either enable researchers to estimate the impact of extra schooling among those who desire to receive more education (Indonesia 1973-78, China 1977-83, Zimbabwe 1980, Malawi 1994, Uganda 1997) or allow one to study the joint effect of extended schooling among those with a high interest in more education in combination with a compulsory schooling reform (Taiwan 1968). Thus, knowledge gained from this reform may have important policy implications for other developing societies that consider increasing the duration of mandatory schooling.

\section{BACKGROUND}

A large body of literature documents that educated individuals are found to be healthier. ${ }^{9}$ In addition to an individual's own schooling, parental education, particularly that of the mother's, has been shown to be a strong predictor of health outcomes (Currie et al. 2010). From a theoretical standpoint, parental education may impact child health via different mechanisms, including productive and allocative efficiency (Grossman 1972; Kenkel 1991), income and occupation (Card 2001; Oreopoulos 2006),

\footnotetext{
${ }^{9}$ See Grossman (2006) for a nice overview of this literature.
} 
assortative mating (Behrman and Rosenzweig 2002), and time preferences (Becker and Mulligan 1997). Efficiency in production, induced by extended education, may allow mothers to have healthier children with a given set of both healthcare and non-healthcare resources. Meanwhile, improvements in allocative efficiency may increase health knowledge and incentivize parents to undertake health behaviors that enhance child health. For instance, more educated mothers may be more likely to seek preventive care and avoid unhealthy dietary practices, and they may be less likely to smoke. Educated individuals may also enjoy a wage premium in the labor market, or match with more educated, healthier, and more affluent partners, which may in turn improve the health of their children. Finally, if more educated individuals gain more utility from their children's future wellbeing, they may invest more in their children as well.

Research focused on showing correlations finds a strong positive association between mother's schooling and good child health in both affluent and developing societies (Thomas, Strauss, and Henriques 1991; Grossman 2006). Children of more educated mothers are found to be healthier at birth as maternal schooling is inversely associated with premature births and low birth weight (Currie and Moretti 2003). In addition, those with more educated mothers are less likely to die during childhood (Cutler, Deaton, and Lleras-Muney 2006).

Although descriptive evidence consistently shows that maternal education is favorably associated with improved child health, findings based on studies addressing the endogeneity of maternal schooling are not uniform. In developed countries, quasi-experimental evidence offers mixed results. Using college openings in the United States as an instrument for women's schooling, Currie and Moretti (2003) find that higher maternal education promotes child health at birth as measured by gestational age and birth weight. They also document that increased perinatal care, reduced smoking, increased likelihood of mother being married, and reduced parity due to college education may serve as potential mediators. Exploiting variation in the implementation of a compulsory schooling reform between municipalities and over time, Grytten, Skau, and Sørensen (2014) examine the impact of mother's education on child health in Norway. They conclude that increased maternal schooling reduces the likelihood of low birth weight even in a 
country with universal healthcare coverage. On the other hand, using the 1947 reform in the United Kingdom as the source of identifying variation, Lindeboom, Llena-Nozal, and van der Klaauw (2009) find little evidence that extended parental education improves child health in terms of birth weight, likelihood of illness at birth, having a chronic condition, having a mental condition, and body mass index. In addition, McCrary and Royer (2011) implement two regression discontinuity designs (RDD), enabled by age-at-school-entry policies in California and Texas, to estimate the effect of women's education on fertility and the health of their children. Although they find that increased educational attainment of women has a small positive effect on mate quality, their results show little evidence supporting the argument that maternal education improves child health.

Literature investigating the role of parental education in the production of child health by using natural experiments in developing countries has yet to settle as different studies reach different conclusions. Exploiting variation in primary school construction between regions and birth cohorts in Indonesia, Breierova and Duflo (2004) estimate the effect of mother's and father's formal schooling on fertility and child health in a working paper. They find that both maternal and paternal education have negative effects on child mortality. Using data from Taiwan, Chou et al. (2010) utilize a compulsory school reform joint with a school construction program to examine the impact of parental education on birth outcomes and child mortality. The Taiwanese government increased the duration of mandatory primary schooling from 6 to 9 years in 1968, and a major school construction program has been implemented to improve school availability and accommodate increased enrollment. Prior to the reform, public secondary schools were available only for students who did well in a highly competitive national exam, and attending private schools was only possible for those who could afford expensive private school fees. Consequently, the reform enabled a large number of students to enroll in secondary schools that could not afford it otherwise (Chou et al. 2010). They obtain exogenous variation in parental education by exploiting differential exposure to the school construction program at the county level in combination with the change in the minimum years of compulsory schooling. Using data on all the births that took place between 1978 and 1999 in Taiwan, Chou et al. (2010) show that an increase in years of 
parental schooling lowers the likelihood of low birth weight and child mortality. Grépin and Bharadwaj (2015) employ Zimbabwe's 1980 education reforms to examine the impact of maternal schooling on child mortality using data from the DHS of Zimbabwe. To increase primary and secondary schooling, the government undertook a number of changes, including constructing new schools and the introduction of free and compulsory primary education for all. Exploiting age specific exposure to Zimbabwe's education reform of 1980 (i.e., being younger than 15 in 1980) as an instrument for years of schooling (as well as having some secondary education), Grépin and Bharadwaj (2015) find that mother's extended schooling causes a decline in child mortality. Lastly, Makate and Makate (2016) estimate the causal effect of primary schooling on child health by using the elimination of tuition fees as the source of identifying variation. They find that an increase in maternal schooling lowers child mortality.

Even though the aforementioned studies show favorable effects of maternal education on child health in developing nations, a few recent articles, making use of natural experiments, fail to show that maternal education favorably impacts child health. Keats (2014) exploits the elimination of primary school fees beginning 1997 in Uganda to estimate the impact of women's education on child health. Using data from DHS Uganda, this study finds little evidence that maternal education lowers child mortality while it shows that an increase in mother's schooling has a positive effect on offspring's likelihood of receiving immunizations and preventive care. Zhang (2014) uses high school closures as a predictor of female education to examine the effect of maternal schooling on child health in China. She does not find much evidence that mother's high school education reduces the probability of prematurity, low birth weight, neonatal mortality, and infant mortality.

Besides the lack of consensus on how maternal schooling impacts child health, different natural experiments used in the literature are only able to approximate the impact of a specific LATE, corresponding to the impact of education among a particular subsample of the population (Angrist and Krueger 1991; Imbens and Angrist 1994). Distinguishing how different types of education reforms shape the relationship between schooling and health among different groups of individuals is particularly important in developing countries as such knowledge may be critically important in designing educational 
policies (Kremer 2003; Glewwe and Kremer 2006; Glewwe and Muralidharan 2015). The LATEs stemming from most education reforms, employed as the source of identification in studies using data from developing countries, correspond to the impact of education among people with a relatively high tendency to increase their schooling. That is, as summarized in Appendix Table 3, with the exception of Taiwan's education reform of 1968 studied by Chou et al. (2010), all of the natural experiments employed by the above studies generate LATEs which mainly represent the impact of extending schooling among those who had a high desire to receive more education because the incentives provided by these reforms either reduced school fees and/or increased school availability for individuals who could not get more education mainly due to financial constraints. Taiwan's reform in 1968 enables one to study the combined impact of compulsory schooling and reduction in the cost of educational attainment. As noted by Chou et al. (2010), in addition to an increase in the duration of mandatory years of minimum schooling, the education reform in Taiwan dramatically reduced the cost of attending school for a large number of individuals who wanted to continue their schooling beyond a six-year basic education. Consequently, there is a gap in the literature and thus a need for studies identifying the impact of mandatory maternal schooling on child health using data from a developing country.

Furthermore, many of the available studies suffer from limited statistical power because of small sample sizes, as well as a lack of statistically or economically significant relationships between the associated natural experiment and the endogenous schooling variable. For example, although the results of Breierova and Duflo (2004) are intuitive, the first stage estimates of the impact of school construction on years of education do not seem to meet the power requirements for an ideal instrumental variable as shown by the values of the first-stage F-statistics (i.e., these values are usually less than 3 rather than the preferred minimum value of 10). Hence, the authors treat their findings as preliminary. Non-availability of large data sets is a particular limitation in the literature examining the relationship between parental schooling and child wellbeing in developing countries as well. That is, because the mean values of key outcome variables (e.g., low birth weight and child mortality) are usually 5 to 7 percent or lower and the natural experiments at hand only affect a fraction of individuals who are in the treatment group (e.g., 
typically less than 25 percent), even in a study with 8,000 to 10,000 observations, the results may be driven by a handful of observations. ${ }^{10}$ Therefore, estimates based on such small (or even moderately large) sample sizes should be treated with caution as they may be biased. ${ }^{11}$ In Appendix Table 3, we summarize the existing studies providing causal evidence on the relationship between parental schooling and child health in developing societies. Excluding Chou et al. (2010), most studies rely on either moderate (Zhang 2014; Grépin and Bharadwaj 2015) or considerably small (Güneş 2015; Keats 2014) sample sizes, or a weak first stage relationship between the associated natural experiments and formal education (Breierova and Duflo, 2004).

Note that utilizing the 1997 education reform, Güneş (2015) examined the effects of maternal education on child health using a convenience sample from the Turkish Demographic and Health Surveys (TDHS). This study relies on regional differences in schooling capacity, expressed in terms of number of teachers at the province level, in combination with the 1997 education reform, which increased the duration of mandatory basic education from 5 to 8 years, as the source of exogenous variation in schooling. ${ }^{12}$ Güneş (2015) explores the impact of maternal education on child health outcomes and maternal healthcare utilization using data from the TDHS 2008. She finds that maternal education has a

\footnotetext{
${ }^{10}$ For instance, let us assume a case where the sample has 8,000 observations with an equal number of individuals in the treatment and control groups, the mean of the binary dependent variable is 5 percent, and the associated compulsory schooling reform affected 20 percent of the individuals in the treatment group. Therefore, out of 4000 people in the treatment group, there are $800(=4000 * 0.20)$ individuals who are impacted by the schooling reform, and of those there are $40(=800 * 0.05)$ individuals for whom the binary dependent variable equals one. Note that these figures get much smaller as the number of observations in the treatment group gets smaller. Consequently, a handful of observations (usually 2 or 3 out of 40) may dictate results that may be biased.

${ }^{11}$ Because Chou et al. (2010) use aggregate data at the county by year of birth level, this limitation does not apply to them given that their analysis relies on information gathered from a large number of observations (i.e., the full population).

${ }^{12}$ We prefer to employ a fuzzy-RDD type empirical estimation strategy as we believe that it is more appropriate for a number of reasons. First, as illustrated in Figure 1, the implementation of the education reform was completed quickly (i.e., within two years) after the enactment. This identification strategy also relies on much weaker assumptions in comparison to a difference-in-differences estimation strategy. In addition, we argue in Section II that the primary driver of the jump in educational attainment was not the increased school availability, but the mandate of the reform. Therefore, as preferred by a number of other researchers, including Erten and Keskin (forthcoming), Cesur and Mocan (2013), Mocan (2014), Torun (2015), and Dursun and Cesur (2016), we consider that an instrumental variables estimation method enabled by a fuzzy-RDD framework at hand is the most appropriate empirical strategy to study the implications of extended schooling due to the 1997 education reform. Lastly, our estimates are robust to accounting for potential regional and province level differences in the implementation of the reform (in addition to addressing potential convergence in child health at the province level) by controlling for province specific birth cohort trends.
} 
favorable impact on child health (in terms of height-for-age and weight-for-age z-scores and very low birth weight) and mother's likelihood of utilizing healthcare services that may enhance child health. She also estimates the impact of maternal schooling on the likelihood that a child is born with a birth weight below 1500 grams and finds that mother's schooling has a negative effect, which is significant at the 10 percent level.

Even though a data set with a relatively small number of observations may be suitable to obtain population estimates as well as to study the impact of women's education on outcomes with considerably large mean values, the TDHS offers a fairly small sample to study the impact of maternal education on variables that have low average values, such as child mortality and low birth weight. Indeed, in the robustness section of this paper, we formally test the importance of using a sufficiently large sample to estimate the causal effect of parental education on child health outcomes that have small mean values when employing an instrumental variables estimation strategy. This exercise, which is performed in Section VI, documents that, in a small sample (e.g., data from DHS), the instrumental variable estimates of the effect of maternal education on birth outcomes and child mortality may produce biased results. We must stress that our research does not invalidate the contributions of previous studies. To the contrary, our work attempts to address the challenges faced by the broad literature that employs data from developing nations to estimate the causal impact of maternal schooling on child health. Therefore, motivated to fill the gaps in the literature, we examine the causal effect of maternal education on birth outcomes and child mortality by utilizing two large data sets from Turkey that grant us sufficient statistical power. ${ }^{13}$

\footnotetext{
${ }^{13}$ Several studies also examine the causal impact of women's education on fertility using similar identification strategies in different countries (Osili and Long 2008; Andalón, Williams, and Grossman 2014; Geruso and Royer 2014; Lavy and Zablotsky 2015; Fort, Schneeweis and Winter-Ebmer 2016; Güneş 2016). As our focus is on the relationship between maternal schooling and child health, we abstain from delving into the literature examining the impact of women's education on fertility.
} 


\section{DATA}

We use two data sets in our analysis: Birth outcomes data from the Turkish Ministry of Health, and child mortality data from the Turkish Statistical Institute's Population and Housing Census 2011.

\section{Ministry of Health Birth Outcomes Data (MHBOD)}

Information on birth outcomes pertaining to birth weight, gestational age, method of birth delivery, and maternal smoking come from the Ministry of Health. Historically, birth records have not been systematically recorded in Turkey. ${ }^{14}$ With the aim of gaining accurate information on women's and children's health, in 2008 the Ministry of Health initiated a collection of data on birth and maternal outcomes through the Family Medicine Program (FMP), which provides universal primary care to all the citizens at Family Health Centers (FHC) regardless of their financial wellbeing. ${ }^{15}$ The Ministry of Health provided the MHBOD for our use at the child level. ${ }^{16}$ The data also provide information on maternal educational attainment categories of each child. ${ }^{17}$ These categories include: no education, elementary school, middle school, high school, college, and graduate degree. ${ }^{18}$ Because the 1997 education reform (i.e., the instrumental variable we employ in the analysis) obliged individuals to earn at least a middle school degree (i.e., at least 8 years of schooling), we coded Middle School equal to one for children whose mothers earned at least a middle school degree, and it is set equal to zero otherwise. Similar to Brunello, Fabbri, and Fort (2013), Dursun and Cesur (2016), and Fort, Schneeweis and Winter-Ebmer (2016),

\footnotetext{
${ }^{14}$ Consequently, there are relatively few articles exploring the determinants of child health, including birth outcomes, in Turkey. More importantly, existing studies rely on small samples, which result in limited statistical power. Indeed, the Turkish Demographic and Health Survey (TDHS), conducted every 5th year since 1988 with a relatively small sample size, has been the major data source for both academic studies and population estimates for a number of health indicators, including fertility, birth outcomes, and child mortality (Celik and Hotchkiss 2000; Hizel and Coskun 2000; Erci 2003; Ergin et al. 2010; Dinçer, Kaushal, and Grossman 2014; Güneş 2015, 2016).

${ }^{15}$ See Cesur et al. (2017) for a detailed description of the FMP.

${ }^{16}$ Unfortunately, the MHBOD do not include information on maternal birth history, such as birth order.

${ }^{17}$ While it would have been informative for our purposes, data on paternal education are not available.

${ }^{18}$ As is the case in nearly all data sets collected by governmental organizations in Turkey, the MHBOD does not include information on years of schooling (Dursun and Cesur 2016). Because our instrumental variable, the 1997 education reform, specifically mandates earning at least a middle school diploma, this is not an issue particularly to the extent that sheepskin effects, where degrees obtained are more relevant to returns to education than actual years of education (Hungerford and Solon 1987), apply to nonpecuniary benefits.
} 
which limit the analysis sample to birth cohorts who were born a few years before and after the pivotal birth cohort, we restrict the estimation sample to children whose mothers were born 5 years before and after $1986 .^{19}$

Using the available information provided by the MHBOD, we created measures of child health at birth based on birth weight in grams and gestational age. Following the existing literature (Currie and Moretti 2003), we construct two binary low birth weight indicators Low Birthweight and Very Low Birthweight, besides using natural log of birth weight, Log of Birthweight, as a measure of child health at birth. Low Birthweight is set equal to one for children who weigh less than 2500 grams at birth, and it is set equal to zero otherwise. Very Low Birthweight is constructed analogously using 1500 grams as the cut-off birth weight.

While low birth weight is usually the main concern and more prevalent than high birth weight, a sizable literature in obstetrics, epidemiology, and medicine associates high birth weight with not only short run maternal and child health complications (i.e., birth delivery problems, newborn morbidity, birth injuries), but also long run health ailments including overweight/obesity in late childhood (Boulet et al. 2003; Zhang et al. 2008; Cnattingius et al. 2012; Sparano et al. 2013), type 2 diabetes (Wei et al. 2003; Whincup et al. 2008), cardiovascular and metabolic complications (Walsh and McAuliffe 2012), and reduced cognitive outcomes (Cesur and Kelly 2010). Similarly, maternal diabetes, glucose intolerance, maternal overweight prior to pregnancy, gestational weight gain, gestational age, previous history of macrosomic birth, maternal age (>30) (Sparano et al. 2013; Walsh and McAuliffe 2012; Koyanagi et al. 2013; Retnakaran et al. 2012), and gender of the child (Walsh and McAuliffe 2012) are listed as determinants of high birth weight. In order to investigate the effect of maternal education on high birth weight we generated a High Birthweight variable, equal to one if the infant weighs more than 4500 grams, and zero otherwise.

\footnotetext{
${ }^{19} \mathrm{We}$ also test the robustness of our findings to alternate bandwidth selections (i.e., from $\pm 6, \pm 4$, and \pm 3 years). As we show in Table 6 , this exercise did not cause any appreciable change in our main findings.
} 
Gestational age in weeks is calculated by taking the difference between the date of birth and the date of last menstruation. Using the standard definition from the World Health Organization, Premature is defined as being equal to one if a child's gestational age is less than 37 weeks, and it is coded as zero otherwise. ${ }^{20}$ We also employ natural "Log of Gestational Age" as an outcome variable.

While the Ministry of Health aims to collect data on all births in the country, the extent of the MHBOD are limited by the reach of the FMP. Note that the FMP started as a pilot program in 2005 in one province, and it was expanded to all of the 81 provinces in Turkey by 2010. As discussed extensively by Cesur et al. (2017), the purpose of the introduction of the FMP was to provide universal primary healthcare services to all citizens free of charge. Therefore, the MHBOD may have some limitations as well. First, because the nationwide expansion of the FMP was completed during 2010, the MHBOD could only be collected in a subsample of provinces prior to 2011 even though the data collection effort was initiated in 2008. Second, although the FMP aims to cover everyone in the country regardless of income and socio-economic status, not all citizens will choose to receive the services offered by the FMP. Lastly, MHBOD are collected by healthcare professionals employed at family health centers (FHC), through which the FMP program is administered. Therefore, while the MHBOD provides information on a large number of births between 2008 and 2016, it does not include all of them due to weak enforcement on data collection by the Ministry of Health in addition to staffing shortages at FHCs, which hinder data collection efforts. Nevertheless, despite the aforementioned limitations, the MHBOD is ideal for our purposes and provides us with a large sample to analyze the impact of maternal education on child health. To begin with, depending on the birth outcome, our data provide information on about 82 percent of all the births that took place since 2011, the year at which the FMP was in full effect in all provinces. Furthermore, we also formally test whether the data availability for birth weight, method of birth delivery, and gestational length is a function of the instrumental variable we employ. Accordingly, we estimated the effect of exposure to the 1997 education reform on the likelihood of having missing information for each child health and maternal outcome defined above. If being bound by the compulsory schooling

${ }^{20}$ See http://www.who.int/mediacentre/factsheets/fs363/en/. 
reform impacts the likelihood of reporting information on birth and maternal outcomes, our instrumental variable estimates may be biased. Therefore, this test is particularly important for our purposes. Results presented in Appendix Table 4 show that the estimated coefficients on education reform are both very small in magnitude and statistically insignificant; thus, the likelihood of having missing information on outcome measures is unrelated to exposure to the 1997 education reform. All in all, these exercises increase our confidence in the suitability of the MHBOD for examining the impact of maternal education on child outcomes.

\section{Population and Housing Census 2011 (PHC)}

Data on child mortality are obtained from the PHC, conducted by the Turkish Statistical Institute (TurkStat). Until 2000, a general population census, which collected information from all the residents, was conducted on a regular basis. ${ }^{21}$ To enhance the provision of public goods and services via more accurate planning, the TurkStat established the Address Based Population Census (ABPC) in 2007, which also replaced the regular census. Since the establishment of ABPC, demographic characteristics, including population, age and gender structure, marital status, educational attainment, place of registration, within country migration, and nationality of individuals have been closely monitored through administrative sources and updated on an annual basis. While the ABPC provides detailed information on these measures, it does not collect some internationally recommended and nationally needed data on a number of social, economic, demographic, and housing characteristics of the population.

Therefore, the TurkStat decided to implement a mini census in order to collect information unavailable in the ABPC, such as labor force, employment, unemployment, reasons for migration, disability, and building and dwelling characteristics. The PHC was conducted by face-to-face interviews of more than two million households and about nine million people in 2011. As we noted previously, we limit the analysis sample and focus our attention on women who were born between 1981 and 1991 .

\footnotetext{
${ }^{21}$ The first census was conducted in 1927, four years after the establishment of the Republic of Turkey. Then starting in 1935, censuses were organized every five years until 1990, and the last census was conducted in 2000.
} 
Like the MHBOD, instead of years of completed schooling, the PHC provides us with educational attainment categories, which include no education, elementary school, middle school, high school, college and graduate school. Thus, Middle School, which is the key independent variable in the PHC data as well, is coded as one for women who earned at least a middle school degree, and zero otherwise.

We set Any Child Died equal to 1 if the respondent mother had at least one child deceased before the age of five, and it is equated to 0 if she had no children passed away before the age five. Although it would be informative to examine the impact of maternal schooling on neonatal (i.e., death in the first four weeks of life) and infant (i.e., death in the first year of life) mortality, one limitation of the PHC data set is that it only provides information on child mortality by age five. While the lack of information on infant mortality per se is a disadvantage, child mortality statistics released by the TurkStat suggest that the vast majority of child deaths in Turkey occur in the first year of life. More specifically, in 2011, even though the mortality rate of infants was 11.7 in a 1000, the mortality rate among ages 1 to 5 was less than 1 in a 1000. Therefore, for the most part, the child mortality information provided by the PHC is likely to be driven by and thus also reflect infant mortality.

\section{ECONOMETRIC METHODOLOGY}

Using the MHBOD at the child level, equation (1) estimates the relationship between maternal schooling and birth outcomes:

$B O_{i}=\gamma_{0}+\gamma_{1}(\text { Middle School })_{i}+\boldsymbol{X}_{\boldsymbol{i}}^{\prime} \boldsymbol{\gamma}+u_{i}$

where $B O$ is child i's associated birth outcome, including birth weight, gestational age, and premature birth status. Using the MHBOD, we also estimate the impact of women's education on method of birth delivery and maternal smoking. The key independent variable, Middle School, is a dichotomous indicator 
representing whether child i's mother earned at least a middle school degree. The vector $X$ contains predetermined covariates, which are province fixed effects, mother's month of birth indicators, child's birth year fixed effects, and linear approximations of mother's birth year-month on each side of the pivotal birth cohort of 1986, thus controlling for maternal age at the birth of the child. The idiosyncratic error term is denoted by $u$. Controlling for province fixed effects accounts for all the unobserved determinants of female education and the outcome of interest common to everyone living in the same province. Maternal month-of-birth fixed effects account for seasonality in mother's birth (Torun and Tumen 2015).

In equation (2), we use data at the mother level from the PHC to examine the relationship between mother's education and child mortality:

$C M_{m}=\beta_{0}+\beta_{1}(\text { Middle School })_{m}+\boldsymbol{X}_{\boldsymbol{m}}^{\prime} \boldsymbol{\theta}+\varepsilon_{m}$

where $C M$ represents whether mother $m$ had at least one child died by the age of 5. The remaining covariates of equation (2) are constructed analogously to equation (1).

Estimating the parameters of equations (1) and (2) using ordinary least squares (OLS) may not necessarily correspond to the causal effect of maternal schooling on child health given that unobservable determinants of maternal education may also determine birth outcomes and child mortality. For instance, more educated mothers may come from high SES families and possess both genetic and behavioral advantages leading to biased estimates of the effect of maternal education on child outcomes.

In order to estimate the causal impact of maternal education on child outcomes, we make use of a two-stage least squares estimation strategy. In doing so, we instrument mother's educational attainment on the 1997 education reform, which is used as the source of exogenous variation in maternal education. Equations (3) and (4) correspond to the first stage estimates of the impact of the 1997 education reform on 
the likelihood of maternal middle school completion for the child level birth outcomes, and mother level child mortality specifications, respectively:

$$
\begin{aligned}
& \text { Middle School }_{i}=\alpha_{0}+\alpha_{1} \text { Reform }_{i}+\boldsymbol{X}_{\boldsymbol{i}}^{\prime} \boldsymbol{\alpha}+\emptyset_{i} \\
& \text { Middle School }_{m}=\pi_{0}+\pi_{1} \text { Reform }_{m}+\boldsymbol{X}_{m}^{\prime} ¥+\Omega_{i}
\end{aligned}
$$

where the outcome is Middle School. Reform is a dichotomous variable which captures whether the mother was exposed to the reform (i.e., it is set equal to one if she was born after 1986, and zero otherwise). All other variables mimic those specified in equations (1) and (2). In the second stage, we use Reform as an instrument for Middle School and estimate 2SLS models to approximate the causal impact of maternal middle school education on child health.

Our identification strategy hinges upon the assumption that pre- and post-reform cohorts (i.e., control and treatment groups) have similar observable and unobservable characteristics except their extended primary schooling induced by exposure to the 1997 reform. This premise becomes more convincing as the estimation window around the cutoff birth year gets smaller (Lee and Lemieux, 2010). Therefore, we limit our estimation sample to individuals who were born 5 years before and after 1986 . Nevertheless, to ensure the robustness of our findings to using different data intervals, we also report results using bandwidths of $\mp 6, \mp 4$, and $\mp 3$ years around the cutoff birth cohort. As pointed out earlier, because the treatment status of the 1986 cohort is ambiguous, we drop the 1986 cohort from our main analysis. $^{22}$

In all specifications, standard errors clustered at the mother's birth year by province level, leading to $810(=81 * 10)$ cluster units. Birth outcome models are weighted using province level number of women

\footnotetext{
${ }^{22}$ Eliminating the 1986 birth cohort also accounts for the potential spillover effects and the possible lag between the timing of legislation and implementation as well. Moreover, according to data from the World Bank, approximately $5 \%$ of primary school students repeated a grade in the mid-1990s; excluding 1986 may also help in accounting for this group. However, as presented in Table 5, inclusion of the 1986 birth cohort with alternative treatment values (such as Reform $=0.25$ ) does not alter our main findings.
} 
in the age of fertility (i.e., ages 15 to 49 ). We use the weights provided by the PHC in child mortality specifications.

\section{RESULTS}

\section{Summary Statistics}

Table 1 presents summary statistics for the MHBOD (in Panel A) and PHC (in Panel B) data sets by exposure to the 1997 education reform status. Children whose mothers were born between 1981 and 1985 constitute the control group, and the 1987 to 1991 birth cohorts form the treatment group. Panel A in Table 1 highlights the difference in education levels between the treatment and control groups in birth weight data; while $57 \%$ of mothers obtained at least a middle school diploma in the treatment group, this percentage is $49.5 \%$ in the control group. Mean birth weight is 3,246 grams. Very Low Birthweight and High Birthweight categories make up $1 \%$ of our birth weight sample, while six percent of women gave birth to low birth weight babies (i.e., under 2500 grams). As expected, the prevalence of very low birth weight, low birth weight, and high birth weight babies are all lower in the treatment group compared to the control group. The average gestational age is around 38 weeks; as expected, there were fewer premature births in the treatment group (11\%) compared to the control group (12\%).

As displayed in Panel B of Table 1, we observe a jump in the proportion of women who hold at least a middle school degree in the treatment group compared to the control group for the PHC data as well. Panel B of Table 1 also shows that $1.9 \%$ of women in the treatment group, and $2.9 \%$ of the women in the control group, declare that at least one of their children died before the age of five.

\section{OLS Estimates of Child Health on Maternal Schooling}

In Table 2, we show the associations between child health and mother's schooling. In Panel A, maternal education is positively associated with a healthy birth weight. Specifically, infants whose mothers earned at least a middle school degree have a 0.50 percent higher birth weight, and 0.48 and 0.30 percentage-point less likely to weigh below 2500 and above 4500 grams, respectively. We also find that 
maternal education is associated with a 0.24 percent decrease in the length of gestation and 0.95 percentage point decrease in the likelihood of premature births. We do not find a statistically significant relationship between parental education and head circumference at birth.

In Panel B, we find that children of mothers who hold at least a middle diploma are 1.9 percentage points less likely to have died by age 5 .

While the OLS estimates are helpful in observing the descriptive nature of the relationship between maternal education and the health of the offspring, whether these results reflect the causal effect of education on child health is debatable. Numerous observable and unobservable common determinants of maternal schooling and child outcomes, including income, genetic makeup of the mother, and access to medical care, may bias the estimates of the coefficient on schooling. To get a handle around the potential endogeneity of maternal education, we next employ an instrumental variable (IV) estimation strategy, in which Middle School is regressed on the 1997 education reform.

\section{The Impact of the 1997 Education Reform on Maternal Schooling}

As noted above, the 1997 education reform obliged individuals born after 1986 to obtain at least a middle school degree. Figure 1 provides visual illustrations of the impact of Reform on Middle School by the estimation sample. ${ }^{23}$ Accordingly, we observe an unambiguous jump in the proportion of mothers with at least a middle school diploma among those who were bound by the compulsory schooling reform, regardless of the estimation sample.

In Appendix Figures 2 and 3, we provide additional evidence on validating our empirical design as suggested by Lee and Lemieux (2010). First, as a standard procedure of our empirical design, we show that some of the potential predetermined variables are balanced across the 1986 cutoff. While the data we use in this study do not provide us with a rich set of predetermined variables, we are able to employ disability status and cohort size variables, which are not expected to be impacted by exposure to the

\footnotetext{
${ }^{23}$ More specifically, we visualize the impact of being exposed to reform on completing at least a middle school degree by netting out the influence of pre-determined variables and plotting the residuals for pre-and post-reform cohorts based on Equations (3) and (4) (Lee and Lemiux 2010; Brunello, Fabbri, and Fort 2013).
} 
reform, to descriptively test the "balanced covariates" assumption. Evidently, as Appendix Figure 2 shows, there is no significant jump across the 1986 cutoff. Second, in Appendix Figure 3, we provide the visual representation of the McCrary test, which provides evidence that the non-random sorting of the running variable, month of birth, across the 1986 threshold is rejected and is continuous around the cutoff. ${ }^{24}$ This provides additional support for the exogeneity of our IV.

The strength of our IV is formally tested in Table 3, where we analyze the effect of exposure to the education reform on the likelihood of earning a middle school diploma at the minimum. Results suggest that the reform increased middle school graduation between 8 to 23 percentage points, depending on the estimation sample. In each case, the estimated coefficient on Reform is statistically significant at the one percent level. While these first stage effect sizes are in the range of other studies examining the impact of the 1997 education reform on a number of outcomes (Cesur and Mocan 2013; Torun 2015; Dursun and Cesur 2016), the impact of the reform on educational attainment is greater in the PHC sample in comparison to the MHBOD sample. We revisit and address this issue in the robustness section below by performing a two sample instrumental variables estimation strategy.

\section{The Impact of Maternal Education on Child Health}

Baseline IV estimates of the impact of maternal educational attainment on birth outcomes, and child mortality are presented in Table 4 . The first stage F statistics shown here are well above the recommended value of 10 , revealing the strength of our IV.

In Panel A, Middle School causes a decline in the probability that a child is born with a birth weight of below 1,500, and 2,500 grams by 4.7, and 7.4 percentage points, respectively. Results also show that mothers who hold at least a middle school diploma are 2.7 percentage points less likely to have a baby with a high birth weight (> 4,500 grams). These findings show that maternal education increases the likelihood that a child is born with a healthy birth weight, which also explains why the effect of

\footnotetext{
${ }^{24}$ The p-values of the estimated jumps are 0.312 and 0.202 for the birth weight sample and the mortality sample, respectively.
} 
Middle School on Log Birthweight is positive but small (3.7 percent) and marginally statistically

significant. Next, we show that maternal education increases the duration of gestation by 2.3 percent, and it lowers the likelihood of premature births by 5 percentage points. Note that the IV estimate switches the sign on log gestation age, which suggests that the observed negative relationship in OLS specifications may be due to selection bias. ${ }^{25}$ Mother's middle school education also increases child's head circumference at birth by (a statistically insignificant) 1.3 percent. When we evaluate these results jointly, we reach the conclusion that compulsory maternal schooling has a causal favorable effect on child health at birth.

In Panel B, we estimate the causal effect of extended maternal primary schooling on child mortality. In line with the evidence presented in Panel A of Table 4 (i.e., improved child health at birth), we find that children of mothers who earned at least a middle school degree are 1.8 percentage points less likely to have died by age 5 .

\section{ROBUSTNESS, HETEROGENEITY, AND TWO SAMPLE IV ESTIMATES}

\section{Robustness}

We perform a number of robustness checks to test the sensitivity of our baseline estimates. In our first robustness exercise, in column (2) of Table 5, we present the reduced form estimates of the impact of maternal exposure to the 1997 education reform on child outcomes. ${ }^{26}$ These results are fully in line with the 2SLS estimates. Furthermore, the reduced form estimates are more precisely estimated and statistically significant for each specification we estimate. ${ }^{27}$

As there is some uncertainty with respect to whether those born in 1986 were bound by the compulsory schooling reform, we excluded the 1986 birth cohort from our benchmark analysis. In column (3), we assigned an alternate treatment value to (i.e., Reform=0.25) with respect to exposure to the 1997

\footnotetext{
${ }^{25}$ For example, the negative sign on OLS estimates presented in Table 2 may be due to C-section birth deliveries being performed around 38-39 weeks of pregnancy.

${ }^{26}$ To simplify comparison, we also present the baseline IV estimates in the first column of Table 5.

${ }^{27}$ The IV estimates can be obtained by dividing these intent-to-treat estimates of the impact of the education reform by the associated first stage estimate.
} 
education reform for those who were born in $1986 .{ }^{28}$ These estimates are very similar to our baseline findings.

In our main specifications, we accounted for birth cohort trends by controlling for maternal birth month-year differentiated by exposure to the education reform status. We check if our baseline estimates change when we specify maternal birth month-year quadratically. As seen in column (4) of Table 5, these results are nearly identical to our main findings.

Given that our empirical methodology is consistent with a fuzzy regression discontinuity design (Lee and Lemieux 2010), we next examine if our results are robust to undertaking the formal RD estimation procedure using local linear regressions. In doing so, we estimate our models with the procedure described by Calonico, Cattaneo, and Titiunik (2014) and Calonico et al. (2016a,b). ${ }^{29}$ As presented in column (5) of Table 5, the linear RD IV estimates are qualitatively and quantitatively similar to our baseline findings.

We next test the robustness of our estimates to accounting for the potential regional heterogeneity in how extended maternal schooling due to the reform impacted child health. To do so, we interact binary province indicators with women's birth month-year and specify them in our regressions. Controlling for province specific birth cohort trends also accounts for any bias that may stem from convergence in child outcomes between provinces (and regions) over the years. Because developing countries have exhibited relatively fast improvements in health outcomes in the past few decades, one may question whether our findings are driven by potential convergence in child outcomes between different regions. Thus, ruling out the role of convergence in our framework is particularly informative. Results presented in column (6) show that when we control for province specific trends, the estimated effect of extended primary schooling is estimated with greater precision. These estimates show that our findings are not driven by

\footnotetext{
${ }^{28}$ Assigning alternate treatment values for those born in 1986 (e.g., Reform=0, and Reform=0.33) produces very similar results.

${ }^{29}$ Moreover, instead of five-year static bandwidths, we estimated our models with optimal bandwidths obtained by the default MSE-optimal bandwidth selector introduced by Calonico et al. (2014, 2016a,b). The estimates we obtained from this procedure are completely in line with our benchmark findings, and are available upon request from the authors.
} 
convergence in child outcomes by maternal birth year between regions. Instead, this exercise suggests that failing to control for province specific trends may lead to imprecise estimates of the impact of maternal education on child outcomes.

An important issue in statistical inference for regression analysis is the possibility that standard errors are correlated within clusters. In such cases, standard errors may be estimated with bias, which in turn may lead to false conclusions (Cameron, Gelbach, and Miller 2015). As we previously discussed, school starting age in Turkey is primarily determined by a child's birth year. In addition, the mandate of the reform may have differential effects on educational attainments of individuals residing in different parts of the country. Therefore, in line with Agüero and Bharadwaj (2014), Cesur and Mocan (2013), and Grépin and Bharadwaj (2015), we adjust the standard errors at the mother's birth year by province level. We next explore if the statistical inference in our main specifications are robust to adjusting the standard errors at other cluster units. These estimates are presented in Appendix Table 5. Specifically, we cluster the standard errors on the province (in column 1), birth year-month (column 2), birth year-month by province (column 3), birth year by region (column 4), and birth year (column 5), respectively. While we employ a large number of cluster units in columns (1) to (5), standard errors are adjusted for 10 cluster units in column (5). To address the potential bias that may be induced by employing few cluster units when adjusting the standard errors on the year of birth, we perform a wild-cluster bootstrapping method as suggested by Cameron, Gelbach, and Miller (2008). As shown in column (6), this exercise has no bearing on our main conclusions. ${ }^{30}$

We conducted our main analysis using the sample of individuals born 5 years before and after 1986, which is the pivotal birth cohort. While employing a wider estimation-window boosts statistical power via increasing the sample size, the possibility that the identifying variation comes from individuals who are further away from the discontinuity may threaten the validity of our estimates. Therefore, in

\footnotetext{
${ }^{30}$ We conducted all the empirical analysis of the PHC data in October 2015 in the Data Analysis Center of the TurkStat in Ankara, Turkey. Therefore, in Panel B of Appendix Table 5, we are only able to report standard errors clustered on the province, and birth year-month levels in columns (1) and (2). Nevertheless, the pattern of results presented in Panel A of Appendix Table 5 strongly suggest that the statistical inference for the PHC specifications should be robust to clustering at other levels.
} 
Table 6, we assess whether our preferred estimates (which include province specific birth cohort trends, as shown in column 6 of Table 5) hold when we change the data estimation window. In particular, we estimate our baseline specifications using the sample of individuals born within $6 \pm, 5 \pm, 4 \pm$, and $3 \pm$ years of the pivotal birth cohort of 1986 in columns (1) to (4), respectively. Results displayed in Table 6 document that our findings are robust to bandwidth selection.

Next, we present the graphical illustrations of the effect of the 1997 education reform on outcomes of interest. Such visual summaries are particularly important when the identifying variation in the endogenous variable is obtained from an exogenous discontinuity (Imbens and Lemieux 2008; Lee and Lemieux 2010; Clark and Royer 2013). Figures 2A-2K display the reduced form graphs of the effect of the 1997 compulsory school reform on child health at birth and child mortality. Consistent with the results shown in Table 6, these graphs support the argument that rather than a sporadic jump in the outcome variables, our IV estimates are driven by systematic shifts in child health at birth and child mortality due to mother's extended primary schooling.

We noted that most natural experiments employed in the literature usually influence the schooling behavior of about 25 percent or a smaller fraction of the individuals in the treatment group, and the mean values for child mortality and low birth weight are usually about 0.10 or lower. Therefore, we argued above that the IV estimates of the impact of maternal education on child health indicators with low mean values (e.g., low birth weight and child mortality) may be biased without a sufficiently large sample. To test the validity of this assertion, we use data from the three available waves of the Turkish Demographic and Health Survey (TDHS) collected in 2003, 2008, and 2013 and re-estimate our most comprehensive specifications (shown in Table 6). To do so, we constructed indicators for birth outcomes, which are child mortality, and maternal smoking using the TDHS data in an identical fashion with the variables we used

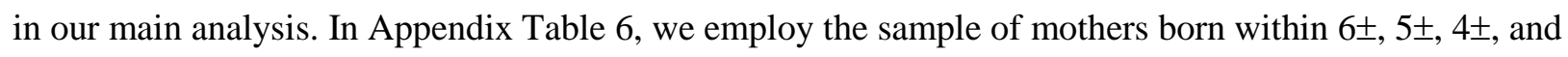
$3 \pm$ years of the pivotal birth cohort in columns (1) through (4). In the TDHS sample, the estimates of birth outcomes, maternal smoking, and child mortality are conducted with 3,365; 6,564; and 4,692 
observations in the largest data interval (column 1) for birth outcomes, maternal smoking and child mortality samples, respectively. Of these observations, 23 to 33 percent are in the treatment group, and about 67 to 77 percent constitute the control group. As displayed in columns (1) to (4) of Appendix Table 6, models using the TDHS are imprecisely estimated in all but one of the cases. More importantly, coefficients have the "wrong sign" for three of four birth weight indicators (i.e., Log Birthweight, Very Low Birthweight, and Low Birthweight) in most cases, and estimates of Very Low Birthweight and Any Child Died on Middle School change signs as we change the data estimation interval. To gain additional statistical power, in column (5) of Appendix Table 6, we estimated our specifications in the TDHS using the sample of individuals born 10 years before and after the pivotal birth cohort. Even though the sample sizes increased by 52 to 70 percent, none of the specifications presented in column (5) is statistically significant although they now carry the expected signs. Consequently, these results provide evidence in favor of the argument that without a sufficiently large estimation sample, IV estimates of the impact of maternal education on child health may be imprecisely estimated and/or biased.

\section{Heterogeneity}

To the degree that our data allow us, we also undertake a few exercises to explore the potential heterogeneity in our estimates. Note that the 1997 education reform aimed to increase the years of schooling of those with a low tendency to extend their schooling beyond five years of basic education. How extended education impacts child outcomes among women who are at the lower tail of the educational attainment distribution is particularly important from the viewpoint of a policymaker. Albeit imperfect, to provide an answer to this question, we reproduce our main models by limiting the estimation sample to those with at most a middle school degree. In Table 7, despite reduced sample sizes, estimates of the impact of maternal education on child outcomes are precisely estimated.

It is commonly observed in developing countries that families may provide less care to their daughters because of son preference (Oster 2009; Bharadwaj and Lakdawala 2013). That is, if parents receive greater utility from their daughters or sons, they may discriminate care in favor of the preferred 
gender when providing antenatal or postnatal care. Therefore, in Table 8, we explore whether the effect of maternal education on child health differs by the gender of the offspring. These estimates show that the gender specific estimates are similar to those using the full sample; hence, the impact of mother's schooling on child health does not seem to depend on child gender.

Extended maternal schooling may have potentially differing effects on child health in different regions. On the one hand, women's education in poorer or more rural regions may be more effective in improving child health if the marginal effect of maternal behavioral modifications on child outcomes is greater especially when formal healthcare is not readily available. For example, such behavioral modifications may become more important if infectious diseases and accidents that are the major causes of child mortality (Chou et al. 2010). On the other hand, educating women with a low schooling tendency may improve their productive efficiency when they have easier access to medical care in more developed or urban areas. Therefore, we also explore if the impact of maternal education on child outcomes differs by region of residence. ${ }^{31}$ Although relatively less precisely estimated, region specific estimates, which are available upon request, show that the impact of maternal education on child outcomes are similar across different geographic areas.

Lastly, while it would have been informative to explore the heterogeneous effects of maternal compulsory schooling on birth outcomes and child mortality in urban versus rural areas, we are unable to run these models as our data sets do not provide information on whether the respondents live in urban or rural localities.

\section{Two Sample IV Estimates in the MHBOD}

The first stage estimates presented in Table 3 show a discrepancy between two data sources we employ. That is, while the reform has a 22.8 percentage point effect on middle school graduation in the

\footnotetext{
${ }^{31}$ A region in the Republic of Turkey includes groups of provinces based on geographic proximity, and economic and social similarities for statistical purposes. The country is divided into 12 regions, which include Istanbul Region, W. Marmara Region, Aegean Region, E. Marmara Region, W. Anatolia Region, Mediterranean Region, Central Anatolia Region, W. Black Sea Region, E. Black Sea Region, Northeast Anatolia Region, Central East Anatolia Region, Southeast Anatolia Region.
} 
PHC data, it is roughly 8 percentage points in the MHBOD sample. To understand why this difference exists, we reached out to a few family physicians, who are in charge of data collection at the Family Health Centers. Accordingly, they reported that family physicians access the date of birth information of mothers and children from the Census Bureau via a computer software. Information on child outcomes, maternal behaviors, and education are reported by mothers. As the main objective of the data collection efforts through the family health centers is to get accurate data on health outcomes, it is very likely that health information is collected with high accuracy.

However, because the terms to describe 5 years of schooling (ilkokul) prior to the reform and 8 years of schooling (Illkögretim) after the reform are not only phonetically similar but also have similar meanings in Turkish language, it is possible that those who were bound by the reform may have inadvertently misreported their educational attainment status. That is, in the Turkish language, the meaning of the word Illkokul is elementary school, and the word Illkögretim means primary education. Recall that the reform united elementary school (Ilkokul) and middle school (Orta Okul) under the roof of primary school (Illkögretim). Therefore, the educational attainment status of those who hold an 8-year primary school diploma may be miscoded as 5-year elementary school diploma due to reporting error. ${ }^{32}$ If the potential measurement error in Middle School variable in the MHBOD is correlated with the 1997 education reform, the IV estimates of $\gamma_{1}$ may be biased.

The standard method to tackle this problem in the literature is to implement a two sample instrumental variables (TSIV) estimation strategy (Angrist and Krueger 1992; Inoue and Solon 2010). In doing so, we used two different data sources to obtain the first stage effect of the law on Middle School. First, we used the first stage from the PHC data which is presented in Panel B of Table 3. Second, we estimate the impact of the 1997 reform on the likelihood of earning at least a middle school diploma among ever married women using data from the Household Labour Force Survey (HLFS) for the period

\footnotetext{
${ }^{32}$ This issue should be of a much smaller concern in the PHC data since the TurkStat carefully trains its survey personnel to minimize potential errors in the TurkStat surveys.
} 
2008-14. ${ }^{33}$ The estimate of the impact of Education Reform on Middle School in the HLFS is displayed in column (1) of Table 9. Accordingly, those who are bound by the reform are 24.5 percentage points more likely to earn at least a middle degree. For ease of presentation, we display the first stage estimate from the PHC data in column (2). It is comforting that the first stage estimate of the effect of law on educational attainment in the HLFS is fairly close to that in the PHC data. In column (3), we present the reduced form impact of the 1997 reform on child health outcomes. Then, in columns (4) and (5) we display the TSIV using the first stage estimates from the HLFS and PHC, respectively. The TSIV coefficients obtained from this exercise is equal to the ratio of the reduced from and the associated first stage coefficient. We use the delta method to calculate the standard errors for these coefficients as summarized in Inoue and Solon (2010). ${ }^{34}$ The estimates presented in columns (4) and (5) are very similar to each other and precisely estimated. Furthermore, as implied by the change in the magnitude of the associated first stage estimate, coefficients obtained from the TSIV estimation method are roughly one third of those presented in previous tables. An additional advantage of the TSIV exercise is that it also allows to correctly evaluate our effect sizes.

In column (5), which provides us with the unbiased effect sizes for the IV estimates in the MHBOD, we find that earning at least a middle school diploma leads to a 1.3 percent increase in birth weight of the offspring. Middle School lowers the likelihood of Very Low Birthweight, Low Birthweight, and High Birthweight by 1.6, 2.5, and 0.9 percentage points, respectively. Furthermore, mothers who possess at least eight years of schooling have a 1.8 percentage point lower likelihood of delivering preterm babies, and experience a 1.5, and 0.4 percent increase in gestational length and head circumference, respectively.

\footnotetext{
${ }^{33}$ The HLFS has been conducted since 1988 by the Turkish Statistical Institute and is the main data source for employment, economic activity, occupation, and other labor market indicators. See http://www.turkstat.gov.tr/ for more information.

${ }^{34}$ More specifically, following Inoue and Solon (2010), and Mocan, Rashke and Unel (2015), we use the delta method to calculate the standard error of the estimated TSIV coefficient, $\gamma_{1}$, as: $\operatorname{var}\left(\gamma_{1}\right)=\left(\frac{1}{\alpha_{1}^{2}}\right)\left[\operatorname{Var}\left(\delta_{1}\right)+\right.$ $\delta 12 \alpha 12 \operatorname{Var}(\alpha 1)$, where $\alpha 1$ is the first stage coefficient in Equation 3 and 4 , and, $\delta 1$ is the corresponding reduced form coefficient.
} 
We also undertook a quick and dirty approach to circumvent the potential issue of mismeasurement of maternal schooling in the MHBOD. Accordingly, we assign different probabilities to the likelihood of middle school graduation rates of women who were born after 1986 and declared that their highest level of completed schooling corresponds to a five-year elementary school degree. In Appendix Table 7, we estimate the impact of maternal schooling on birth outcomes by assigning the values of $1,0.75,0.5$, and 0.25 to the likelihood of earning at least a middle school diploma for those who were bound by the reform and reported their highest level of educational attainment as five years of elementary school diploma in columns (1) to (4), respectively. This exercise produces coefficients which are similar to those obtained from the TSIV estimates and lead to greater precision in the estimated effect of maternal schooling on outcomes of health. More importantly, in column (2), in which the first stage estimate is very similar to those in the HLFS and PHC, the coefficients on Middle School are qualitatively and qualitatively very similar to those obtained from the TSIV.

\section{THE IMPACT OF MATERNAL EDUCATION ON MATERNAL BEHAVIORS}

Does extended primary schooling influence maternal attitudes? While the MHBOD do not contain extensive information on maternal behaviors, the data provide information on method of birth delivery and maternal smoking.

If education impacts women's behaviors during pregnancy in terms of seeking preventive care and/or adherence to recommendations by healthcare professionals, the likelihood of experiencing health complications during child delivery may be reduced (Currie and Moretti 2003; Cutler and Lleras-Muney 2006; McCrary and Royer 2011). Furthermore, while the primary purpose of utilizing non-natural childbirth delivery methods (e.g., C-section, vacuum extraction, forceps delivery) is to prevent potential health complications that may impact the mother and child, C-sections are also preferred by some women due to perceived pain avoidance during birth delivery (Penna and Arulkumaran 2003). Studies have shown that children who are not exposed to maternal bowel flora during birth due to C-section birth delivery may be more likely to face adverse health consequences later in life, including increased risk of 
obesity, asthma, and energy uptake from the gut and immune development (Blustein and Liu 2015; Black et al. 2016). Therefore, women who are more knowledgeable about the subsequent health effects of Csections as a consequence of extended schooling may consider attempting to avoid C-section birth deliveries. Normal Birth, which may capture child health at birth or maternal investment in child health, is a binary variable equal to 1 if the birth delivery was vaginal, and 0 otherwise. Lastly, we construct two maternal smoking measures that may capture mother's health behaviors during pregnancy. Ever Smoked and Current Smoker are dichotomous covariates representing whether the mother ever smoked regularly and whether she was smoker at the time of data collection, respectively. ${ }^{35}$ Descriptive statistics, displayed in Appendix Table 8, show that $46 \%$ of women experienced a normal delivery, and this rate is significantly higher in the treatment group $(52 \%)$ compared to the control group $(42 \%) .{ }^{36}$ Women in the treatment group are less likely to report they have ever smoked or are smoking at the time of the data collection in comparison to women in the control group.

In Table 10, we present the estimates of the relationship between women's education and maternal behaviors. The OLS estimates in column (1) reveal that women with at least eight years of schooling are 11.7 percentage points less likely to deliver babies via natural birth delivery. Given that Csections constitute a large fraction of non-normal birth delivery methods (53.5 percent in our sample), the negative association between maternal education and Normal Birth is consistent with the argument that Csection birth deliveries are preferred by women who earned at least a middle school degree. ${ }^{37}$ This could be due to the potential positive association between women's level of education / age and experiencing complications when giving birth. Meanwhile, it is also possible that as more educated women can financially afford C-sections, perceived pain avoidance during delivery may partially explain the

\footnotetext{
${ }^{35}$ While it would have been informative to know the status of women's tobacco use during pregnancy, our data do not allow us to make such a distinction.

${ }^{36}$ Turkey has a disproportionately high rate of C-sections compared to the world average (Akarsu and Mucuk 2014; Zeldin 2012; Seckiner, Tezcan, and Tunckanat 2010). C-sections are an important option, particularly when the mother or infant is facing a life-threatening situation during labor or delivery. Yet it is riskier than vaginal delivery and has a longer recovery period. In spite of this, many Turkish women prefer C-sections to vaginal births, partly due to "labor pain and fear" (Akarsu and Mucuk 2014).

${ }^{37}$ In an unreported specification, we also estimated the likelihood of C-section on Middle School. In line with the OLS estimate of Normal Birth, we find that women who completed at least eight years of schooling are 12 percentage points more likely to use $\mathrm{C}$-section as the method of birth delivery.
} 
observed positive association. High prevalence of C-section may also explain the negative association between maternal education and gestational age as C-section surgeries are usually performed at around 38-39 weeks of gestation (Davidoff et al. 2006; Wilmink et al. 2010). In column (1), we also explore the associations between women's education and smoking behavior. This can be a mechanism through which maternal education is linked to child health. We find that women who hold at least a middle school diploma are 2 and 0.9 percentage points more likely to have ever smoked cigarettes and smoke at the time of data collection, respectively. This finding is consistent with the observed positive association between education and female smoking in middle-income countries (Cutler and Lleras-Muney, 2012). As discussed by Cutler and Lleras-Muney (2012), this pattern is likely to represent the social context of female smoking in such countries, including women's empowerment and social acceptability.

In column (2) we present the IV estimates of the impact of female schooling on maternal behaviors. Children with mothers who earned at least a middle school diploma are 24.8 percentage points more likely to be delivered via normal birth. This finding is in stark contrast to the OLS estimate presented in column (1), in which we found that maternal education was negatively correlated with the likelihood of a normal birth delivery. Different factors can explain why an increase in maternal educational attainment has a positive impact on normal birth delivery. First, likely due to improvements in allocative efficiency, access to maternal care, and increased income, if maternal education induces mothers to exhibit health improving behaviors during pregnancy, the chances of experiencing health complications during birth delivery may diminish. For instance, we already showed that maternal schooling has a causal negative impact on high birth weight, which is a well-known reason to employ non-normal birth delivery methods. Moreover, if more educated mothers are more aware of the child health benefits of a vaginal birth delivery, they may choose to avoid unnecessary C-sections.

When we turn our attention to maternal smoking, in column (2) we find that receiving at least eight years of schooling lowers the likelihood of ever smoking regularly and being a current smoker by 8.4 and 3.4 percentage points, respectively. Given that women's smoking is found to have negative 
effects on child health, these results suggest that the avoidance of risky health behaviors by mothers may mediate the relationship between maternal education and child health. ${ }^{38}$

In columns (3) to (7) we display the reduced form effect of education reform on maternal attitudes and perform the TSIV estimates. Then, we repeat the robustness and sensitivity exercises that we performed for child health outcomes in Figures 3A-3C, and Appendix Tables 9, 10 and 11. These exercises produce a very similar pattern to that of birth outcomes and child mortality. These estimates suggest increased schooling among women improves their behaviors towards enhancing the health of their offspring's. Altogether, these findings boost our confidence of the findings pertaining to the main focus of our study, which show that extended maternal schooling improves child health at birth and lower child mortality.

\section{DISCUSSION AND CONCLUSIONS}

A number of researchers in economics have explored whether parental (particularly maternal) schooling has a causal effect on child health in developing nations. Although some of these studies document that extending mother's years of schooling improves child health at birth and lowers child mortality, a set of others does not find a statistically or economically significant relationship between the two. A closer look at these studies reveals that a key shortcoming of many of the studies in this literature is the lack of adequate statistical power. Even when the source of identifying variation in maternal education comes from a credible natural experiment, without a sufficiently large estimation sample, the results may be biased especially when the mean of the dependent variable is small. Furthermore, previous literature offers little knowledge on the impact of forcing those with a little interest to pursue additional schooling to receive extra education in developing countries.

\footnotetext{
${ }^{38}$ Nevertheless, if extra schooling causes women to under-report their smoking to healthcare professionals especially, our estimates may be biased away from zero (or from a potential positive impact of education on smoking). Therefore, caution should be exhibited in interpreting the impact of women's education on maternal smoking.
} 
To fill the void in the literature, we analyze the effect of maternal compulsory schooling on child health using two large data sets from a developing country, the Republic of Turkey. We exploit the 1997 compulsory education reform as our source of exogenous variation in maternal schooling to address the endogenous nature of mother's education. We analyze a host of outcomes, including birth weight, gestation, head circumference, child mortality, method of birth delivery, and maternal smoking.

Our findings show that mothers who earned at least a middle school diploma are less likely to give birth to babies with very low birth weight, low birth weight, and high birth weight. They are less likely to have a child died by age five. Additionally, obtaining increased schooling extends gestational age and lowers the propensity of delivering premature babies. Finally, we also find evidence suggesting that additional extended primary education increases the likelihood of normal births and decreases maternal smoking.

To put the estimates in context and be able to compare to other studies examining the relationship between maternal education and child health in developing countries, we calculated the impact of at least one additional year of maternal education, which is obtained by dividing our estimates by three given that the 1997 education reform led to an increase of at least three years of education among those who are impacted by the law. Our results imply that at least one more year of maternal education lowers the probability of very low birthweight by 0.53 percentage points, low birth weight by 0.83 percentage points, and high birthweight by 0.3 percentage points. It lowers the probability of premature birth by 0.6 percentage points and the probability of child mortality by 0.6 percentage points. We also find evidence that it increases the probability of a normal birth by 3.3 percentage points and lowers the probability of maternal smoking by 1.33 percentage points. Our results survive a number of robustness checks. ${ }^{39}$ These effect sizes are similar to those reported by Grépin and Bharadwaj (2015) and Chou et al. (2010).

Our careful analysis addresses potential concerns surrounding the validity of our instrumental variable. As illustrated by our graphical analysis, figures reveal a discontinuity around the reform for our

\footnotetext{
${ }^{39}$ These effect sizes on birth outcomes and maternal smoking are obtained using the estimates presented in column 5 of Table 9. The effect size on child mortality is shown in Table 5 (column 6) and also in Table 6 (column 2).
} 
outcome variables yet no discontinuity for the balancing covariates, lending further support for the strength of our instrument in the first stage and the validity of exclusion restrictions. The consistency of our results across the estimates of various models, including different econometric specifications, functional forms, choice of bandwidth, different samples, as well as the inclusion of province specific birth cohort trends, among other robustness checks, suggests that our findings represent the causal effect of having obtained a middle school degree on child health outcomes.

Importantly, our estimates correspond to the LATE of maternal education on birth outcomes and child mortality among mothers with a low tendency to extend their education beyond five years of basic schooling in the absence of the mandate of the law. The 1997 education reform in Turkey is a unique one in developing countries for the reason that it allows one to estimate the policy implications of compulsory schooling at the lower end of the educational attainment distribution. Note that, as we previously discussed, some aspects of the 1997 reform may have also reduced the cost of educational attainment and enabled some individuals to afford schooling; thus, the LATE of this study does not perfectly represent the pure effect of extended education among those with no interest in additional schooling. That being said, to the best of our knowledge, this reform provides the closest natural experiment that enables one to study the impact of mandated schooling in a developing country.

While the efforts towards accomplishing universal primary schooling in poorer societies of the world lead to significant progress, many developing countries have relatively few years of mandated education. Furthermore, those with compulsory schooling laws oftentimes fail to successfully enforce the rule, especially for females. Taken together, our findings underscore the role of positive health spillovers of women's education in developing countries in particular, where rates of female educational attainment are significantly lower. Therefore, this research provides strong support for the argument that enacting compulsory schooling laws and enforcing them in developing countries may have large positive externalities in terms of child health. 


\section{REFERENCES}

Agüero, Jorge M., and Prashant Bharadwaj. (2014). Do the more educated know more about health? Evidence from schooling and HIV knowledge in Zimbabwe. Economic Development and Cultural Change 62, no. 3: 489-517.

Angrist, Joshua D., and Alan B. Krueger. (1991) Does Compulsory School Attendance Affect Schooling and Earnings? The Quarterly Journal of Economics 106, no. 4: 979-1014.

Angrist, Joshua D., and Alan B. Krueger. (1992). The effect of age at school entry on educational attainment: an application of instrumental variables with moments from two samples. Journal of the American statistical Association 87, no. 418: 328-336.

Akarsu, Rukiye Hobek, and Salime Mucuk. (2014) Turkish women's opinions about cesarean delivery. Pak J Med Sci. Nov-Dec; 30(6): 1308-1313.

Andalón, Mabel, Jenny Williams, and Michael Grossman (2014). Empowering Women: The Effect of Schooling on Young Women's Knowledge and Use of Contraception. National Bureau of Economic Research Working Paper No. w19961.Cambridge, MA.

Aytaç, Işık A., and Bruce H. Rankin. Modernity, traditionality, and junior high school attainment in Turkey. Social Indicators Research 66, no. 3 (2004): 267-282.

Battistin E, Brugiavini A, Rettore E, Weber G (2009) The retirement consumption puzzle: evidence from a regression discontinuity approach. Am Econ Rev 99:2209-2226.

Becker, Gary S., and Casey B. Mulligan. (1997) The endogenous determination of time preference. The Quarterly Journal of Economics:729-758.

Behrman, Jere R., and Mark R. Rosenzweig. (2002). Does Increasing Women's Schooling Raise the Schooling of the Next Generation? American Economic Review, XCII (March), 323-334.

Bharadwaj, Prashant, and Leah K. Lakdawala. (2013) Discrimination begins in the womb: evidence of sex-selective prenatal investments. Journal of Human Resources 48, no. 1:71-113.

Black, Mairead, Siladitya Bhattacharya, Sam Philip, Jane E. Norman, and David J. McLernon. (2016) Planned Repeat Cesarean Section at Term and Adverse Childhood Health Outcomes: A RecordLinkage Study. PLoS Med 13, no. 3:e1001973.

Blustein, Jan, and Jianmeng Liu. (2015) Time to consider the risks of caesarean delivery for long term child health. BMJ 350:h2410.

Boulet, Sheree L., Greg R. Alexander, Hamisu M. Salihu, and MaryAnn Pass. (2003)Macrosomic births in the United States: determinants, outcomes, and proposed grades of risk. American journal of obstetrics and gynecology 188, no. 5:1372-1378.

Breierova, Lucia, and Esther Duflo (2004). The impact of education on fertility and child mortality: Do fathers really matter less than mothers? National Bureau of Economic Research Working Paper No. w10513.Cambridge, MA. 
Brunello, Giorgio, Daniele Fabbri, and Margherita Fort. (2013) The causal effect of education on body mass: Evidence from Europe. Journal of Labor Economics 31, no. 1:195-223.

Cakir, R., Irfan Bozan and B. Talu. (2004). Imam Hatip Liseleri: Efsaneler ve Gercekler. TESEV, http://www.tesev.org.tr/.

Calonico, Sebastian, Matias D. Cattaneo, and Rocio Titiunik. (2014) Robust Nonparametric Confidence Intervals for RegressionDiscontinuity Designs. Econometrica 82, no. 6 2295-2326.

Calonico, Sebastian, Matias D. Cattaneo, Max H. Farrell, and Rocio Titiunik. (2016a) rdrobust: Software for Regression Discontinuity Designs. Working paper, University of Michigan.

Calonico, Sebastian, Matias D. Cattaneo, Max H. Farrell, and Rocio Titiunik. (2016b). Regression Discontinuity Designs Using Covariates. Working paper, University of Michigan.

Cameron, A. Colin, Jonah B. Gelbach, and Douglas L. Miller. (2008). Bootstrap-based improvements for inference with clustered errors. The Review of Economics and Statistics 90, no. 3: 414-427.

Cameron, A. Colin, and Douglas L. Miller. (2015) A practitioner's guide to cluster-robust inference. Journal of Human Resources 50, no. 2: 317-372.

Card, D. (2001). Estimating the Return to Schooling: Progress on Some Persistent Econometric Problems. Econometrica, 69(5), pp. 1127-60.

Celik, Yusuf, and David R. Hotchkiss. (2000) The socio-economic determinants of maternal health care utilization in Turkey. Social science \& medicine 50, no. 12: 1797-1806.

Cesur, Resul; Kelly, Inas. (2010). From Cradle to Classroom: High Birth Weight and Cognitive Outcomes. Forum for Health Economics and Policy, Vol. 13: Iss. 2 (Health Economics), Article 2.

Cesur, Resul, and Naci H. Mocan. (2013) Does secular education impact religiosity, electoral participation and the propensity to vote for Islamic parties? Evidence from an education reform in a Muslim country. National Bureau of Economic Research Working Paper No. w19769.Cambridge, MA.

Cesur, Resul, Bahadır Dursun, and Naci Mocan. (2014) The impact of education on health and health behavior in a middle-income, low-education country. National Bureau of Economic Research Working Paper No. w20764. Cambridge, MA.

Cesur, Resul, Pınar Mine Güneş, Erdal Tekin, and Aydogan Ulker. The value of socialized medicine: The impact of universal primary healthcare provision on mortality rates in Turkey. Journal of Public Economics 150 (2017): 75-93.

Chou, Shin-Yi, Jin-Tan Liu, Michael Grossman, and Ted Joyce. (2010) Parental education and child health: evidence from a natural experiment in Taiwan. American Economic Journal: Applied Economics 2, no. $133-61$.

Clark, Damon, and Heather Royer. (2013). The Effect of Education on Adult Mortality and Health: Evidence from Britain. American Economic Review103, no. 6: 2087-2120. 
Cnattingius, Sven, E. Villamor, Y. T. Lagerros, Anna-Karin Wikström, and Fredrik Granath. (2012). High birth weight and obesity-a vicious circle across generations. International journal of obesity 36 , no. 10: $1320-1324$.

Currie, Janet, and Enrico Moretti. (2003). Mother's Education and the Intergenerational Transmission of Human Capital: Evidence from College Openings. The Quarterly Journal of Economics 14951532.

Currie, Janet, Mark Stabile, Phongsack Manivong, and Leslie L. Roos. (2010). Child health and young adult outcomes. Journal of Human Resources 45, no. 3: 517-548.

Cutler, David, Angus Deaton and Adriana Lleras-Muney. (2006). The determinants of mortality. Journal of Economic Perspectives 20(3): 97-120.

Cutler, David M., and Adriana Lleras-Muney. (2012). Education and health: insights from international comparisons. National Bureau of Economic Research Working Paper No. w17738. Cambridge, MA.

Davidoff, Michael J., Todd Dias, Karla Damus, Rebecca Russell, Vani R. Bettegowda, Siobhan Dolan, Richard H. Schwarz, Nancy S. Green, and Joann Petrini. (2006). Changes in the gestational age distribution among US singleton births: impact on rates of late preterm birth, 1992 to 2002. In Seminars in perinatology, vol. 30, no. 1, pp. 8-15. WB Saunders.

Dinçer, Mehmet Alper, Neeraj Kaushal, and Michael Grossman. (2014) Women's education: Harbinger of another spring? Evidence from a natural experiment in Turkey. World Development 64: 243258.

Dulger I (2004) Turkey: rapid coverage for compulsory education - the 1997 basic education program. Scaling up poverty reduction: a global learning process. World Bank Conference, Shanghai. Available at: http://siteresources.worldbank.org/INTTURKEY/Resources/361616$1142415001082 /$ Compulsory Education by Dulger.pdf. Accessed 30 October 2016.

Dursun, Bahadır, and Resul Cesur. (2016). Transforming lives: the impact of compulsory schooling on hope and happiness. Journal of Population Economics. July, Volume 29, Issue 3, pp 911-956.

Erçelebi, Hasan. (2000). SEKİZ YILLIK ZORUNLU EĞİTIMİN İÇİNIN DOLDURULMASI. Pamukkale Üniversitesi Eğitim Fakültesi Dergisi 7, no. 7: 91-97.

Erci, Behice. Barriers to utilization of prenatal care services in Turkey. (2003). Journal of Nursing Scholarship 35, no. 3: 269-273.

Ergin, Isil, Hur Hassoy, Feride A. Tanik, and Gokce Aslan. (2010) Maternal age, education level and migration: socioeconomic determinants for smoking during pregnancy in a field study from Turkey. BMC Public Health 10, no. 1: 1.

Erten, Bilge, and Pinar Keskin. (Forthcoming). For Better or for Worse? Education and the Prevalence of Domestic Violence in Turkey. American Economic Journal: Applied Economics.

Fort, Margherita, Nicole Schneeweis, and Rudolf Winter-Ebmer. Is Education Always Reducing Fertility? Evidence from Compulsory Schooling Reforms. The Economic Journal 126, no. 595 (2016): 1823-1855. 
Geruso, Michael, and H. Royer. (2014). The impact of education on family formation: Quasiexperimental evidence from the $u k$. Technical report, mimeo, University of California, Santa Barbara.

Glewwe, Paul, and Michael Kremer. Schools, teachers, and education outcomes in developing countries. Handbook of the Economics of Education 2 (2006): 945-1017.

Glewwe, Paul, and Karthik Muralidharan. (2015). Improving school education outcomes in developing countries: evidence, knowledge gaps, and policy implications. University of Oxford, Research on Improving Systems of Education (RISE).

Grépin, Karen A., and Prashant Bharadwaj. (2015). Maternal education and child mortality in Zimbabwe. Journal of health economics 44: 97-117.

Grossman, Michael. On the concept of health capital and the demand for health. Journal of Political economy 80, no. 2 (1972): 223-255.

Grossman, M. (2006). Education and nonmarket outcomes. In E. A. Hanushek \& F. Welch (Eds.), Handbook of the economics of education (Vol. 1, pp. 577-633): North Holland.

Grossman, Michael. (2015). The Relationship between Health and Schooling: What's New? Nordic Journal of Health Economics 3, no. 1: pp-7.

Grytten, Jostein, Irene Skau, and Rune J. Sørensen. (2014). Educated mothers, healthy infants. The impact of a school reform on the birth weight of Norwegian infants 1967-2005. Social Science \& Medicine 105: 84-92.

Güneş, Pınar Mine. (2015). The role of maternal education in child health: Evidence from a compulsory schooling law. Economics of Education Review, 47, 1-16.

Güneş, Pınar Mine. (2016). The Impact of Female Education on Teenage Fertility: Evidence from Turkey. The BE Journal of Economic Analysis \& Policy 16, no. 1: 259-288.

Hizel, Selda, and Turgay Coskun. (2000). Determinants of Birth Weight: Does Air Pollution Have an Influential Effect? Turkish Journal of Medical Sciences 30, no. 1: 47-54.

Hungerford, T. and Solon, G., (1987). Sheepskin effects in the returns to education. The Review of Economics and Statistics, pp.175-177.

Imbens, Guido W., and Joshua D. Angrist. (1994). Identification and Estimation of Local Average Treatment Effects. Econometrica 62, no. 2: 467-475.

Inoue, Atsushi, and Gary Solon. (2010). Two-sample instrumental variables estimators. The Review of Economics and Statistics 92, no. 3: 557-561.

Imbens, Guido W., and Thomas Lemieux. (2008). Regression discontinuity designs: A guide to practice. Journal of econometrics 142, no. 2: 615-635.

Keats, Anthony. (2014). Women's schooling, fertility, and child health outcomes: Evidence from Uganda's free primary education program. Mimeo, Wesleyan University. 
Kenkel, Donald S. (1991). Health behavior, health knowledge, and schooling. Journal of Political Economy 99, no. 2: 287-305.

Koyanagi, Ai, Jun Zhang, Amarjargal Dagvadorj, Fumi Hirayama, Kenji Shibuya, João Paulo Souza, and Ahmet Metin Gülmezoglu. (2013) Macrosomia in 23 developing countries: an analysis of a multicountry, facility-based, cross-sectional survey. The Lancet 381, no. 9865: 476-483.

Kremer, Michael. (2003). Randomized evaluations of educational programs in developing countries: Some lessons. The American Economic Review 93, no. 2: 102-106.

Lavy, Victor, and Alexander Zablotsky. (2015). Women's schooling and fertility under low female labor force participation: Evidence from mobility restrictions in Israel. Journal of Public

Economics 124: 105-121.

Lee, David S., and Thomas Lemieux. (2010). Regression discontinuity designs in economics. Journal of economic literature 48, no. 2: 281-355.

Lindeboom, Maarten, Ana Llena-Nozal, and Bas van der Klaauw. (2009). Parental education and child health: Evidence from a schooling reform. Journal of health Economics 28, no. 1: 109-131.

Makate, Marshall, and Clifton Makate. (2016) The causal effect of increased primary schooling on child mortality in Malawi: Universal primary education as a natural experiment. Social Science \& Medicine 168: 72-83.

McCrary, Justin, and Heather Royer. (2011) The effect of female education on fertility and infant health: Evidence from school entry policies using exact date of birth. The American economic review 101, no. 1: 158-195.

Mocan, Leyla. (2014). The impact of education on wages: Analysis of an Education Reform in Turkey. Available at SSRN 2537472.

Mocan, Naci, Christian Raschke, and Bulent Unel. (2015). The impact of mothers' earnings on health inputs and infant health. Economics \& Human Biology 19: 204-223.

Oreopoulos, Philip. (2006). Estimating average and local average treatment effects of education when compulsory schooling laws really matter. The American Economic Review 96, no. 1: 152-175.

Osili, Una Okonkwo, and Bridget Terry Long. (2008). Does female schooling reduce fertility? Evidence from Nigeria. Journal of development Economics 87, no. 1: 57-75.

Oster, Emily. (2009). Proximate Causes of Population Gender Imbalance in India. Demography 46(2):325-39.

Otaran, Nur, A. Sayn, F. Güven, I. Gürkaynak, and S. Satakul. A gender review in education, Turkey 2003. Retrieved October 15, 2016, from http://www.unicef.org/turkey/gr/ge21.html.

Penna, L., and S. Arulkumaran. (2003). Cesarean section for non-medical reasons. International Journal of Gynecology \& Obstetrics 82, no. 3: 399-409. 
Rankin, Bruce H., and Işik A. Aytaç. Gender inequality in schooling: The case of Turkey. Sociology of Education 79, no. 1 (2006): 25-43.

Retnakaran, Ravi, Chang Ye, Anthony JG Hanley, Philip W. Connelly, Mathew Sermer, Bernard Zinman, and Jill K. Hamilton. (2012). Effect of maternal weight, adipokines, glucose intolerance and lipids on infant birth weight among women without gestational diabetes mellitus. Canadian Medical Association Journal 184, no. 12: 1353-1360.

Seckiner, Pelin Cagatay; Tezcan, Sabahat; Tunckanat, Hande. Turkey's rising trend in Cesarean section: who are these women? (2010) Paper presented at the 2010 European Population Conference. Available at: http://epc2010.princeton.edu/abstracts/100551. Accessed 30 October 2016.

Sparano, Sonia, Wolfgang Ahrens, Stefaan De Henauw, Staffan Marild, Denes Molnar, Luis A. Moreno, Marc Suling et al. (2013). Being macrosomic at birth is an independent predictor of overweight in children: results from the IDEFICS study. Maternal and child health journal 17, no. 8: 13731381 .

Thomas, Duncan, John Strauss, and Maria-Helena Henriques. (1991) How does mother's education affect child height? Journal of human resources 183-211.

Torun, Huzeyfe. (2015). Compulsory Schooling and Early Labor Market Outcomes in a Middle-Income Country. Central Bank of the Republic of Turkey Working Paper No. 15/34. Available at: http://www.tcmb.gov.tr/wps/wcm/connect/87ae51d6-a895-46ad-a132c4794435d224/wp1534.pdf?MOD=AJPERES\&CACHEID=ROOTWORKSPACE87ae51d6a895-46ad-a132-c4794435d224.

Torun, H. and S. Tumen (2015). The Empirical Content of Season-of-Birth Effects: An Investigation with Turkish Data. Unpublished manuscript, Central Bank of the Republic of Turkey.

Turkish Ministry of National Education (2001). National Education Statistics. State Institute of Statistics, Prime Ministry Republic of Turkey.

UNICEF (2007). Eliminating Gender Disparity in Primary Education: The Case of Turkey. New York: United Nations Children's Fund (UNICEF).

United Nations (2015). The Millennium Development Goals Report, United Nations. Available at: http://www.un.org/millenniumgoals/2015_MDG_Report/pdf/MDG\%202015\%20rev\%20(July\%2 01).pdf. Accessed 31 May 2017.

Walsh, Jennifer M., and Fionnuala M. McAuliffe. (2012). Prediction and prevention of the macrosomic fetus. European Journal of Obstetrics \& Gynecology and Reproductive Biology 162, no. 2: 125130.

Wei, Jung-Nan, Fung-Chang Sung, Chung-Yi Li, Chia-Hsuin Chang, Ruey-Shiung Lin, Chau-Ching Lin, Chuan-Chi Chiang, and Lee-Ming Chuang. (2003). Low birth weight and high birth weight infants are both at an increased risk to have type 2 diabetes among schoolchildren in Taiwan. Diabetes care 26, no. 2: 343-348.

Whincup, Peter H., Samantha J. Kaye, Christopher G. Owen, Rachel Huxley, Derek G. Cook, Sonoko Anazawa, Elizabeth Barrett-Connor et al. (2008). Birth weight and risk of type 2 diabetes: a systematic review. JAMA 300, no. 24: 2886-2897. 
Wilmink, Freke A., Chantal WPM Hukkelhoven, Simone Lunshof, Ben Willem J. Mol, Joris AM van der Post, and Dimitri NM Papatsonis. 2010. Neonatal outcome following elective cesarean section beyond 37 weeks of gestation: a 7-year retrospective analysis of a national registry. American journal of obstetrics and gynecology 202, no. 3: 250-e1.

World Bank (2005). Turkey-education Sector Study: Sustainable Pathways to an Effective, Equitable, and Efficient Education System for Pre-school Through Secondary School Education. Report No. 32450-TU, Washington, DC.

Zeldin, Wendy. (2012) Turkey: Law Restricting Caesarean Births. Library of Congress. Available at: http://www.loc.gov/law/foreign-news/article/turkey-law-restricting-caesarean-births/. Accessed 30 October 2016.

Zhang, Shuang. (2014) Mother's Education and Infant Health: Evidence from High School Closures in China. Working Paper.

Zhang, Xun, Adriana Decker, Robert W. Platt, and Michael S. Kramer. (2008). How big is too big? The perinatal consequences of fetal macrosomia. American journal of obstetrics and gynecology 198, no. 5: 517-e1. 
Figure 1: The Impact of the 1997 Reform on Educational Attainment
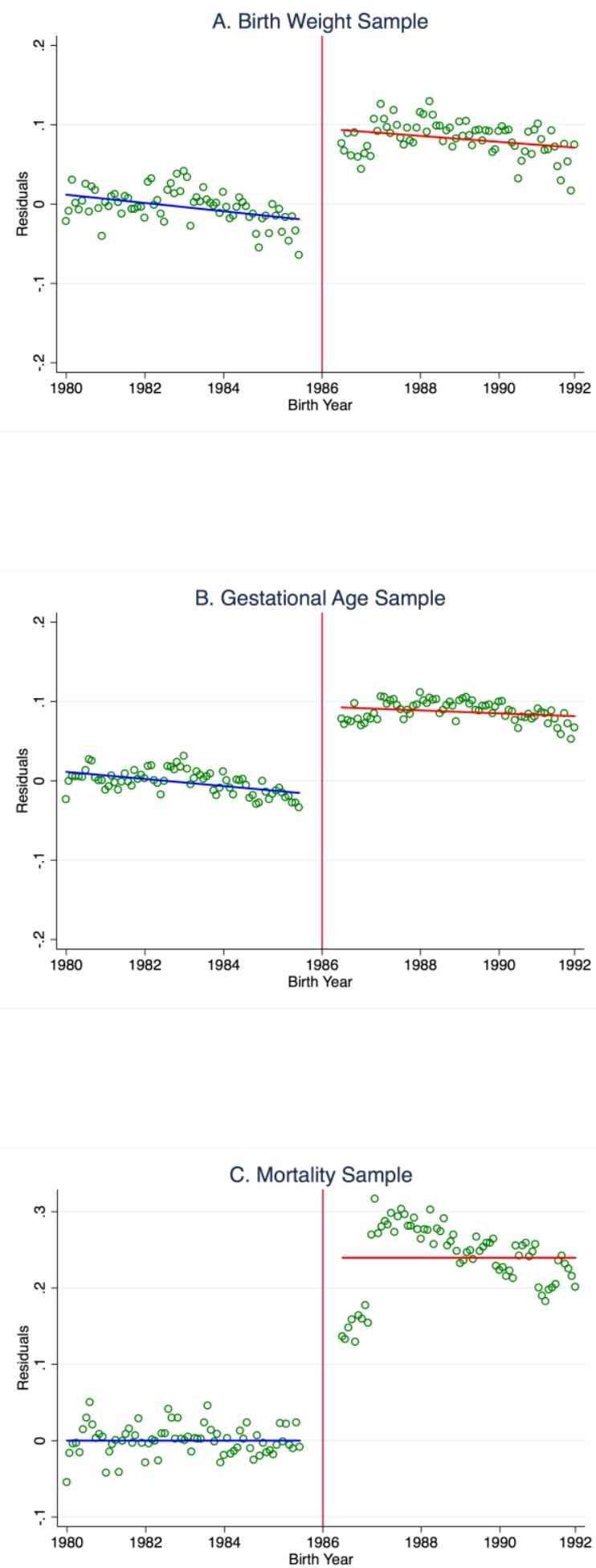


\section{Figure 2: The Impact of the 1997 Education Reform on Outcome Variables}
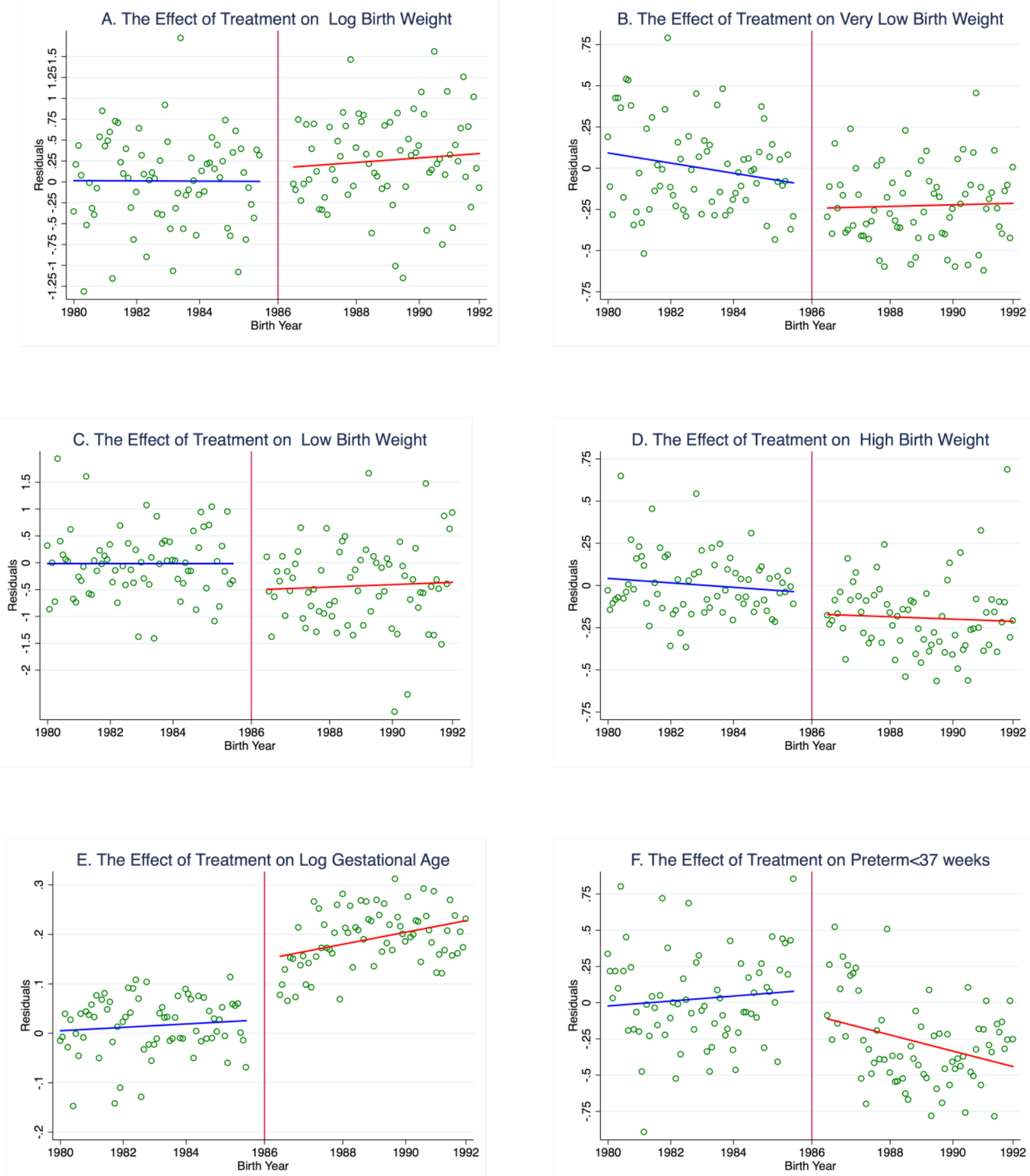
G. The Effect of Treatment on Log Head Circumference

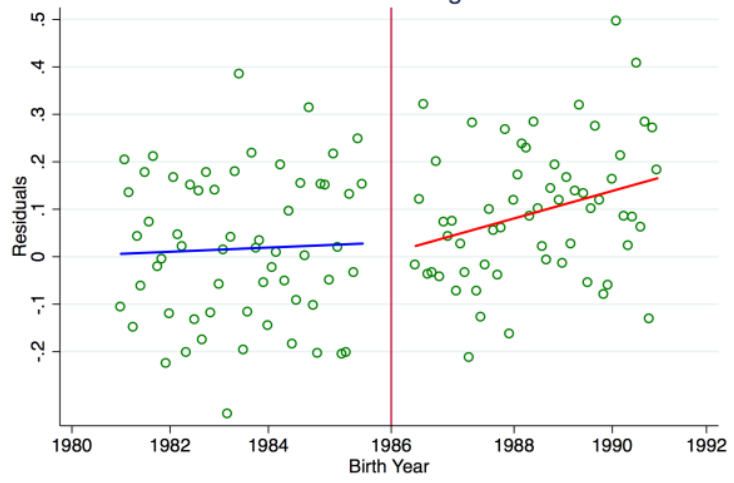

H. The Effect of Treatment on Any Child Died

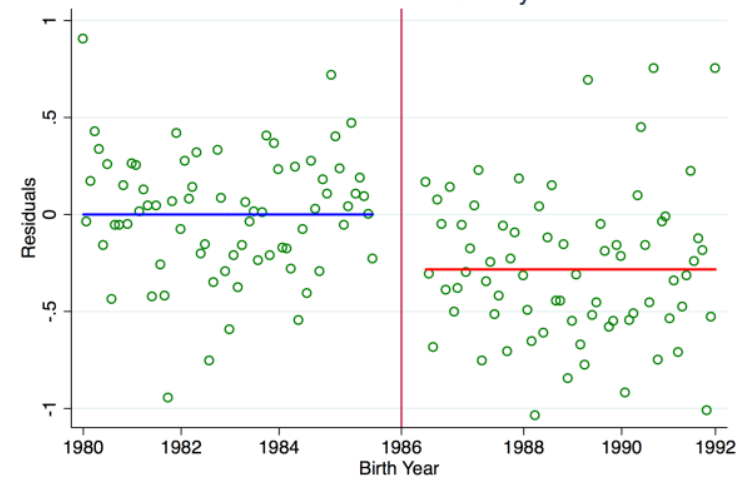


Figure 3: The Impact of the 1997 Education Reform on Maternal Behavior
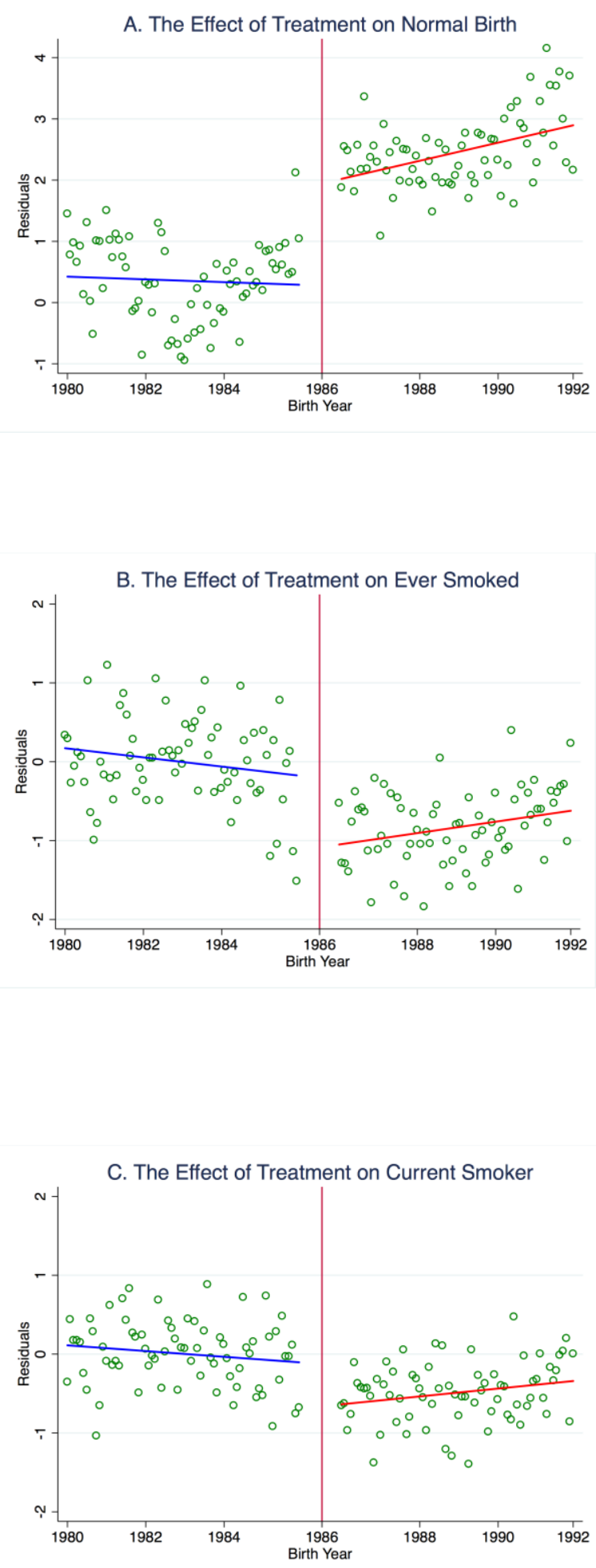
Table 1 Summary Statistics

\begin{tabular}{|c|c|c|c|}
\hline & All & Control & Treatment \\
\hline \multicolumn{4}{|c|}{ Panel A: Birth Outcomes } \\
\hline Middle School & $\begin{array}{l}0.5315 \\
(0.499)\end{array}$ & $\begin{array}{l}0.4951 \\
(0.500)\end{array}$ & $\begin{array}{c}0.5719 \\
(0.4948)\end{array}$ \\
\hline Birth Weight & $\begin{array}{c}3245.947 \\
(502.2491)\end{array}$ & $\begin{array}{c}3260.277 \\
(511.5284)\end{array}$ & $\begin{array}{r}3229.235 \\
(490.6807)\end{array}$ \\
\hline Very Low Birthweight & $\begin{array}{c}0.0055 \\
(0.0742)\end{array}$ & $\begin{array}{c}0.0061 \\
(0.0778)\end{array}$ & $\begin{array}{c}0.0049 \\
(0.0698)\end{array}$ \\
\hline Low Birthweight & $\begin{array}{c}0.0601 \\
(0.2378)\end{array}$ & $\begin{array}{c}0.0607 \\
(0.2388)\end{array}$ & $\begin{array}{c}0.0595 \\
(0.2366)\end{array}$ \\
\hline High Birthweight & $\begin{array}{c}0.0047 \\
(0.0686)\end{array}$ & $\begin{array}{c}0.0058 \\
(0.0761)\end{array}$ & $\begin{array}{c}0.0034 \\
(0.0585)\end{array}$ \\
\hline Age & $\begin{array}{c}26.8181 \\
(3.2559) \\
{[186,840]}\end{array}$ & $\begin{array}{l}29.4389 \\
(1.6383) \\
{[96,874]}\end{array}$ & $\begin{array}{l}23.7617 \\
(1.5753) \\
{[89,966]}\end{array}$ \\
\hline Gestational Age & $\begin{array}{l}38.4173 \\
(2.1752)\end{array}$ & $\begin{array}{l}38.3058 \\
(2.1361)\end{array}$ & $\begin{array}{c}38.541 \\
(2.2111)\end{array}$ \\
\hline Preterm<37 weeks & $\begin{array}{c}0.1169 \\
(0.3213) \\
{[1,486,353]}\end{array}$ & $\begin{array}{c}0.1212 \\
(0.3264) \\
{[756,929]}\end{array}$ & $\begin{array}{c}0.1121 \\
(0.3155) \\
{[729,424]}\end{array}$ \\
\hline Head Circumference & $\begin{array}{c}34.5653 \\
(1.732) \\
{[186,505]} \\
\end{array}$ & $\begin{array}{c}34.5975 \\
(1.749) \\
{[96,689]} \\
\end{array}$ & $\begin{array}{l}34.5278 \\
(1.7113) \\
{[89,816]} \\
\end{array}$ \\
\hline \multicolumn{4}{|c|}{ Panel B: Child Mortality } \\
\hline Middle School & $\begin{array}{l}0.6215 \\
(0.485)\end{array}$ & $\begin{array}{c}0.5438 \\
(0.4981)\end{array}$ & $\begin{array}{c}0.8026 \\
(0.3981)\end{array}$ \\
\hline Any Child Died & $\begin{array}{c}0.026 \\
(0.1591) \\
{[340,091]}\end{array}$ & $\begin{array}{c}0.0291 \\
(0.1681) \\
{[237,964]}\end{array}$ & $\begin{array}{c}0.0188 \\
(0.1359) \\
{[102,128]}\end{array}$ \\
\hline
\end{tabular}

The means in Panel A are generated using data from the Ministry of Health Birth Outcomes Data (MHBOD), and in Panel B, we used Turkish Statistical Institute's Population and Housing Census 2011 (PHC). Individuals born between 1987 and 1991 constitute the treatment group and those who were born between 1981 and 1985 form the control group. Standard deviations are in parentheses. Variables in Panel A are weighted by number of women in fertility age (ages 15 to 49 ) in the province. Survey weights provided by the PHC are used in Panel B. Number of observations are in square brackets []. 
Table 2

OLS Estimates of Child Health and Maternal Health Outcomes on Maternal Education

\begin{tabular}{cc}
\hline \multicolumn{2}{c}{ Panel A: Birth Outcomes } \\
\hline Dependent Variables & \\
\hline Log Birthweight & $0.0050^{* * *}$ \\
& $(0.0016)$ \\
Very Low Birthweight & -0.0004 \\
Low Birthweight & $(0.0007)$ \\
& $-0.0048^{* *}$ \\
High Birthweight & $(0.0021)$ \\
& $-0.003^{*}$ \\
Observations & $(0.0007)$ \\
\hline Log Gestational Age & {$[186,840]$} \\
& $-0.0024^{* * *}$ \\
Preterm<37 weeks & $(0.0002)$ \\
& $-0.0095^{* * *}$ \\
Observations & $(0.001)$ \\
\hline Log Head Circumference & {$[1,486,353]$} \\
& -0.0006 \\
Observations & $(0.0004)$ \\
\hline & {$[186,505]$} \\
\hline Any Child Died & $-0.019 * * *$ \\
& Panel B: Child Mortality \\
Observations & {$[0.001)$} \\
\hline
\end{tabular}

The entries in parentheses are standard errors of the estimated coefficients, clustered at the birth year by province level. *,**, and *** indicate statistical significance at the $10 \%, 5 \%$, and $1 \%$ levels, respectively. All models include re-centered birth date in months differentiated by exposure to the 1997 reform status, mother's month of birth dummies, and province fixed effects. Birth outcome models also control for child's birth year fixed effects and male child dummy. Birth outcome models are weighted by number of women in fertility age (ages 15 to 49 ) in the province. Survey weights provided by the PHC are used in mortality estimations. Number of observations are in square brackets []. 
Table 3

The Impact of the 1997 Education Reform on Obtaining at Least a Middle School Degree Panel A: Birth Outcomes

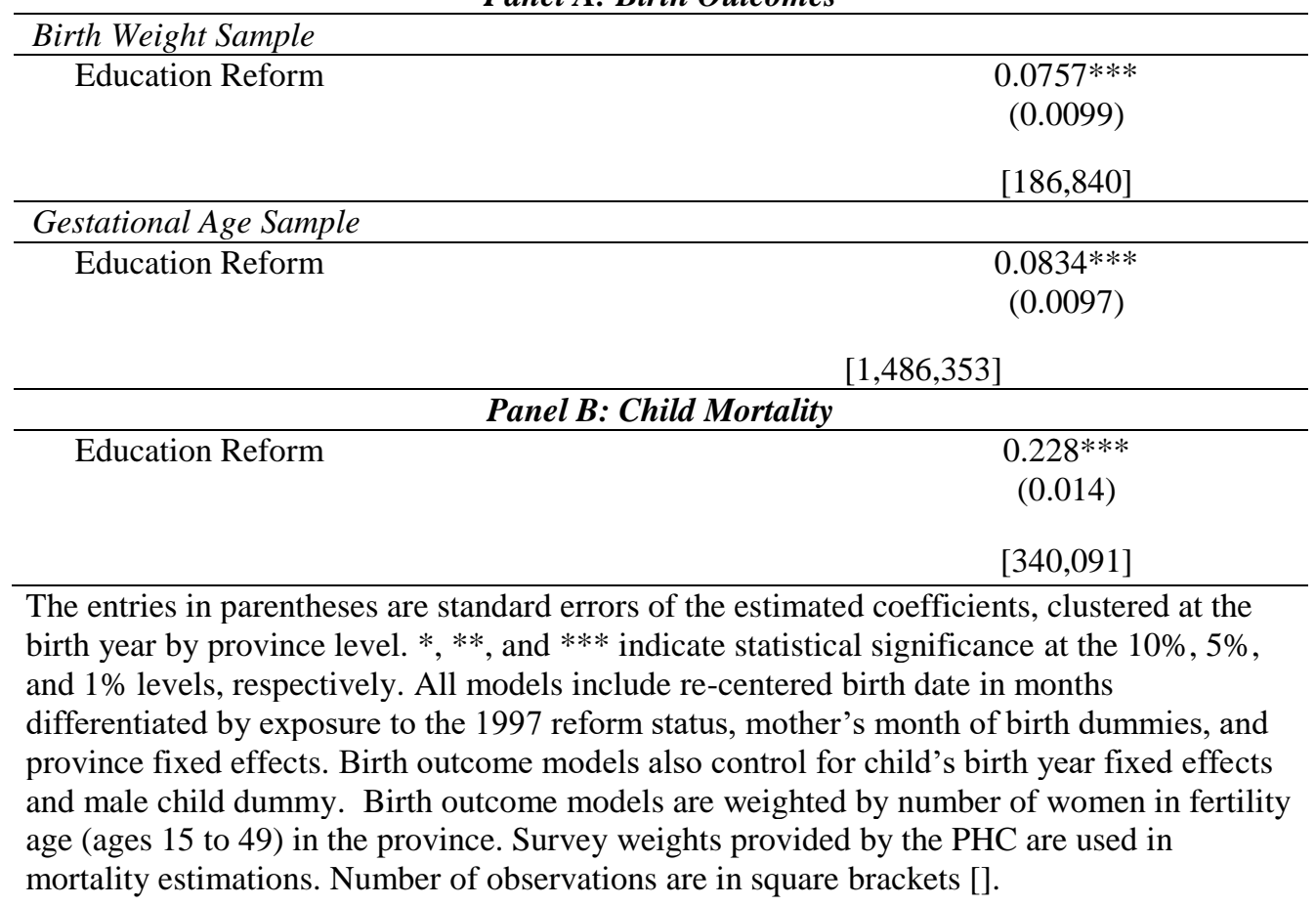


Table 4

Instrumental Variable Estimates of the Impact of Maternal Education on Child Health: Baseline Results

\begin{tabular}{cc}
\hline \multicolumn{2}{c}{ Panel A: Birth Outcomes } \\
\hline Dependent Variables & \\
\hline Log Birthweight & $0.037^{*}$ \\
& $(0.022)$ \\
Very Low Birthweight & $-0.047^{* * *}$ \\
& $(0.012)$ \\
Low Birthweight & $-0.074^{* *}$ \\
High Birthweight & $(0.031)$ \\
& $-0.027^{* *}$ \\
1st Stage F-test & $(0.011)$ \\
& $\{36.835\}$ \\
Log Gestational Age & {$[186,840]$} \\
& $0.023^{* * *}$ \\
Preterm<37 weeks & $(0.004)$ \\
& $-0.050^{* * *}$ \\
1st Stage F-test & $(0.014)$ \\
& $\{74.464\}$ \\
Log Head Circumference & {$[1,486,353]$} \\
& 0.013 \\
1st Stage F-test & $(0.008)$ \\
& $\{37.341\}$ \\
& {$[186,505]$} \\
\hline Any Child Died & $-0.018^{* *}$ \\
1st Stage F-test & $(0.007)$ \\
& $\{232.883\}$ \\
\hline
\end{tabular}

The entries in parentheses are standard errors of the estimated coefficients, clustered at the birth year by province level. *,**, and *** indicate statistical significance at the $10 \%, 5 \%$, and $1 \%$ levels, respectively. All models include re-centered birth date in months differentiated by exposure to the 1997 reform status, mother's month of birth dummies, and province fixed effects. Birth outcome models also control for child's birth year fixed effects and male child dummy. Birth outcome models are weighted by number of women in fertility age (ages 15 to 49 ) in the province. Survey weights provided by the PHC are used in mortality estimations. Number of observations are in square brackets []. $1^{\text {st }}$ Stage F-Statistics are provided in curly brackets \{\} . 
Table 5

The Impact of Maternal Education on Child Health, Robustness Checks

\begin{tabular}{|c|c|c|c|c|c|c|}
\hline & $\begin{array}{c}(1) \\
\text { Baseline } \\
\text { Estimates }\end{array}$ & $\begin{array}{c}(2) \\
\text { Intent to } \\
\text { Treat } \\
\text { Estimates }\end{array}$ & $\begin{array}{c}(3) \\
\text { Alt. Treatment } \\
\text { for 1986 Birth } \\
\text { Cohort } \mathrm{T}==0.25\end{array}$ & $\begin{array}{c}\text { (4) } \\
\text { Quadratic BC } \\
\text { Control } \\
\text { Function } \\
\end{array}$ & $\begin{array}{c}(5) \\
\text { Local Linear IV } \\
\text { with rdrobust } \\
\text { command }\end{array}$ & $\begin{array}{c}\text { (6) } \\
\text { With Province } \\
\text { Specific Birth } \\
\text { Cohort Trends } \\
\end{array}$ \\
\hline \multicolumn{7}{|c|}{ Panel A: Birth Outcomes } \\
\hline \multicolumn{7}{|l|}{ Dependent Variables } \\
\hline Log Birthweight & $\begin{array}{l}0.037^{*} \\
(0.022)\end{array}$ & $\begin{array}{c}0.00287 * * \\
(0.00123)\end{array}$ & $\begin{array}{c}0.046 * * \\
(0.023)\end{array}$ & $\begin{array}{l}0.038 \\
(0.026\end{array}$ & $\begin{array}{c}0.033 * * \\
(0.015\end{array}$ & $\begin{array}{c}0.038 * * \\
(0.019)\end{array}$ \\
\hline Very Low Birthweight & $\begin{array}{c}-0.047 * * * \\
(0.012)\end{array}$ & $\begin{array}{c}-0.00355 * * * \\
(0.00056)\end{array}$ & $\begin{array}{c}-0.039 * * * \\
(0.011)\end{array}$ & $\begin{array}{c}-0.046 * * * \\
(0.011)\end{array}$ & $\begin{array}{c}-0.041 * * * \\
(0.01)\end{array}$ & $\begin{array}{c}-0.047 * * * \\
(0.011)\end{array}$ \\
\hline Low Birthweight & $\begin{array}{c}-0.074 * * \\
(0.031)\end{array}$ & $\begin{array}{c}-0.00563 * * * \\
(0.00171)\end{array}$ & $\begin{array}{c}-0.077^{* *} * \\
(0.03)\end{array}$ & $\begin{array}{c}-0.073^{* *} \\
(0.033)\end{array}$ & $\begin{array}{c}-0.06 * * * \\
(0.023)\end{array}$ & $\begin{array}{c}-0.074 * * \\
(0.029)\end{array}$ \\
\hline High Birthweight & $\begin{array}{c}-0.027 * * \\
(0.011)\end{array}$ & $\begin{array}{c}-0.00200 * * * \\
(0.00073)\end{array}$ & $\begin{array}{c}-0.027 * * * \\
(0.01)\end{array}$ & $\begin{array}{c}-0.026^{* *} \\
(0.011)\end{array}$ & $\begin{array}{c}-0.026 * * * \\
(0.01)\end{array}$ & $\begin{array}{c}-0.026 * * * \\
(0.01)\end{array}$ \\
\hline 1st Stage F-test & $\begin{array}{c}\{36.835\} \\
{[186,840]} \\
\end{array}$ & [186,840] & $\begin{array}{c}\{43.903\} \\
{[208,424]} \\
\end{array}$ & $\begin{array}{c}\{36.538\} \\
{[186,840]} \\
\end{array}$ & {$[186,840]$} & $\begin{array}{c}\{58.66\} \\
{[186,840]} \\
\end{array}$ \\
\hline Log Gestational Age & $\begin{array}{c}0.023 * * * \\
(0.004)\end{array}$ & $\begin{array}{c}0.00190 * * * \\
(0.0002)\end{array}$ & $\begin{array}{c}0.021 * * * \\
(0.004)\end{array}$ & $\begin{array}{c}0.023 * * * \\
(0.004)\end{array}$ & $\begin{array}{c}0.020 * * * \\
(0.004)\end{array}$ & $\begin{array}{c}0.023 * * * \\
(0.003)\end{array}$ \\
\hline Preterm $<37$ weeks & $\begin{array}{c}-0.050 * * * \\
(0.014)\end{array}$ & $\begin{array}{c}-0.00414 * * * \\
(0.00116)\end{array}$ & $\begin{array}{c}-0.057 * * * \\
(0.015)\end{array}$ & $\begin{array}{c}-0.052 * * * \\
(0.016)\end{array}$ & $\begin{array}{c}-0.037 * * * \\
(0.013)\end{array}$ & $\begin{array}{c}-0.050 * * * \\
(0.014)\end{array}$ \\
\hline 1st Stage F-test & $\begin{array}{c}\{74.464\} \\
{[1,486,353]}\end{array}$ & $\begin{array}{c}--- \\
{[1,486,353]}\end{array}$ & $\begin{array}{c}\{77.535\} \\
{[1,654,931]}\end{array}$ & $\begin{array}{c}\{72.681\} \\
{[1,486,353]}\end{array}$ & {$[1,486,353]$} & $\begin{array}{c}\{147.562\} \\
{[1,486,353]}\end{array}$ \\
\hline Log Head Circumference & $\begin{array}{c}0.013 \\
(0.008)\end{array}$ & $\begin{array}{c}0.00100 * \\
(0.00053)\end{array}$ & $\begin{array}{l}0.016^{*} \\
(0.009)\end{array}$ & $\begin{array}{c}0.013 \\
(0.009)\end{array}$ & $\begin{array}{c}0.011 \\
(0.008)\end{array}$ & $\begin{array}{c}0.013 * \\
(0.008)\end{array}$ \\
\hline 1st Stage F-test & $\begin{array}{c}\{37.341\} \\
{[186,505]} \\
\end{array}$ & $\begin{array}{c}--- \\
{[186,505]}\end{array}$ & $\begin{array}{r}\{44.374\} \\
{[208,043]} \\
\end{array}$ & $\begin{array}{c}\{37.078\} \\
{[186,505]} \\
\end{array}$ & {$[186,505]$} & $\begin{array}{c}\{59.373\} \\
{[186,505]} \\
\end{array}$ \\
\hline \multicolumn{7}{|c|}{ Panel B: Child Mortality } \\
\hline Any Child Died & $\begin{array}{c}-0.018 * * \\
(0.007) \\
\{232.883\} \\
{[340,091]}\end{array}$ & $\begin{array}{c}-0.004 * * \\
(0.001) \\
--- \\
{[340,091]}\end{array}$ & $\begin{array}{c}-0.018 * * * \\
(0.007) \\
\{218.5\} \\
{[375,433]}\end{array}$ & $\begin{array}{c}-0.019 * * * \\
(0.006) \\
\{232.198\} \\
{[340,091]}\end{array}$ & $\begin{array}{c}-0.017 * * \\
(0.008) \\
\\
{[340,091]}\end{array}$ & $\begin{array}{c}-0.018 * * * \\
(0.006) \\
\{374.9\} \\
{[340,091]}\end{array}$ \\
\hline
\end{tabular}

The entries in parentheses are standard errors of the estimated coefficients, clustered at the birth year by province level. *, **, and *** indicate statistical significance at the $10 \%, 5 \%$, and $1 \%$ levels, respectively. All models include re-centered birth date in months differentiated by exposure to the 1997 reform status, mother's month of birth dummies, and province fixed effects. Birth outcome models also control for child's birth year fixed effects and male child dummy. Birth outcome models are weighted by number of women in fertility age (ages 15 to 49 ) in the province. Survey weights provided by the PHC are used in mortality estimations. Number of observations are in square brackets []. ${ }^{\text {st }}$ Stage F-Statistics are provided in curly brackets \{\} . 


\section{Table 6}

Robustness of the IV Estimates of the Impact of Maternal Education on Child Health to Using Alternative Bandwidths

\begin{tabular}{|c|c|c|c|c|}
\hline & $\begin{array}{c}(1) \\
80-92 \\
\end{array}$ & $\begin{array}{c}(2) \\
81-91 \\
\end{array}$ & $\begin{array}{c}(3) \\
82-90 \\
\end{array}$ & $\begin{array}{c}(4) \\
83-89 \\
\end{array}$ \\
\hline \multicolumn{5}{|c|}{ Panel A: Birth Outcomes } \\
\hline \multicolumn{5}{|l|}{ Dependent Variables } \\
\hline Log Birthweight & $\begin{array}{l}0.028^{*} \\
(0.017)\end{array}$ & $\begin{array}{c}0.038 * * \\
(0.019)\end{array}$ & $\begin{array}{l}0.030^{*} \\
(0.017)\end{array}$ & $\begin{array}{c}0.037 * * \\
(0.016)\end{array}$ \\
\hline Very Low Birthweight & $\begin{array}{c}-0.030 * * * \\
(0.011)\end{array}$ & $\begin{array}{c}-0.047 * * * \\
(0.011)\end{array}$ & $\begin{array}{c}-0.044 * * * \\
(0.011)\end{array}$ & $\begin{array}{c}-0.045^{* * * *} \\
(0.010)\end{array}$ \\
\hline Low Birthweight & $\begin{array}{c}-0.055^{* *} \\
(0.025)\end{array}$ & $\begin{array}{c}-0.074 * * \\
(0.029)\end{array}$ & $\begin{array}{c}-0.065^{* *} * \\
(0.026)\end{array}$ & $\begin{array}{c}-0.050^{* *} \\
(0.023)\end{array}$ \\
\hline High Birthweight & $\begin{array}{c}-0.027 * * * \\
(0.009)\end{array}$ & $\begin{array}{c}-0.026^{* * * *} \\
(0.010)\end{array}$ & $\begin{array}{c}-0.030 * * * \\
(0.010)\end{array}$ & $\begin{array}{l}-0.019 \\
(0.012)\end{array}$ \\
\hline 1st Stage F-test & $\begin{array}{c}\{66.797\} \\
{[214,185]} \\
\end{array}$ & $\begin{array}{c}\{58.660\} \\
{[186,840]} \\
\end{array}$ & $\begin{array}{r}\{82.271\} \\
{[154,533]} \\
\end{array}$ & $\begin{array}{l}\{176.673\} \\
{[119,450]}\end{array}$ \\
\hline Log Gestational Age & $\begin{array}{c}0.021 * * * \\
(0.003)\end{array}$ & $\begin{array}{c}0.023 * * * \\
(0.003)\end{array}$ & $\begin{array}{c}0.020 * * * \\
(0.003)\end{array}$ & $\begin{array}{c}0.018^{* * * *} \\
(0.004)\end{array}$ \\
\hline Preterm< 37 weeks & $\begin{array}{c}-0.036 * * * \\
(0.012)\end{array}$ & $\begin{array}{c}-0.050 * * * \\
(0.014)\end{array}$ & $\begin{array}{c}-0.027 * * * \\
(0.010)\end{array}$ & $\begin{array}{c}-0.042 * * * \\
(0.014)\end{array}$ \\
\hline 1st Stage F-test & $\begin{array}{c}\{155.373\} \\
{[1,710,454]}\end{array}$ & $\begin{array}{c}\{147.562\} \\
{[1,486,353]}\end{array}$ & $\begin{array}{c}\{203.758\} \\
{[1,227,026]}\end{array}$ & $\begin{array}{l}\{279.901\} \\
{[947,857]}\end{array}$ \\
\hline Log Head Circumference & $\begin{array}{l}0.012^{*} \\
(0.007)\end{array}$ & $\begin{array}{l}0.013^{*} \\
(0.008)\end{array}$ & $\begin{array}{c}0.008 \\
(0.008)\end{array}$ & $\begin{array}{c}0.014^{*} \\
(0.008)\end{array}$ \\
\hline 1st Stage F-test & $\begin{array}{c}\{67.835\} \\
{[213,807]} \\
\end{array}$ & $\begin{array}{c}\{59.373\} \\
{[186,505]} \\
\end{array}$ & $\begin{array}{r}\{82.894\} \\
{[154,257]} \\
\end{array}$ & $\begin{array}{l}\{177.573\} \\
{[119,231]}\end{array}$ \\
\hline \multicolumn{5}{|c|}{ Panel B: Child Mortality } \\
\hline Any Child Died & $\begin{array}{c}-0.015 * * \\
(0.006)\end{array}$ & $\begin{array}{c}-0.018 * * * \\
(0.006)\end{array}$ & $\begin{array}{c}-0.018^{* *} \\
(0.007)\end{array}$ & $\begin{array}{c}-0.017 * \\
(0.009)\end{array}$ \\
\hline 1st Stage F-test & $\begin{array}{c}\{407.0\} \\
{[406,046]}\end{array}$ & $\begin{array}{c}\{374.9\} \\
{[340,091]}\end{array}$ & $\begin{array}{c}\{354.0\} \\
{[269,958]}\end{array}$ & $\begin{array}{c}\{342.5\} \\
{[204,549]}\end{array}$ \\
\hline
\end{tabular}

The entries in parentheses are standard errors of the estimated coefficients, clustered at the birth year by province level. *,**, and *** indicate statistical significance at the $10 \%, 5 \%$, and $1 \%$ levels, respectively. All models include re-centered birth date in months differentiated by exposure to the 1997 reform status, mother's month of birth dummies, and province fixed effects and province specific maternal birth month-year trends. Birth outcome models also control for child's birth year fixed effects and male child dummy. Birth outcome models are weighted by number of women in fertility age (ages 15 to 49 ) in the province. Survey weights provided by the PHC are used in mortality estimations. Column headings pertains to data estimation intervals based on year of birth year of the mother. Number of observations are in square brackets []. $1^{\text {st }}$ Stage F-Statistics are provided in curly brackets \{\} . 
Table 7

Instrumental Variable Estimates of the Impact of Maternal Education on Child Health, at Most Middle School Sample

\begin{tabular}{cc}
\hline & Panel A: Birth Outcomes \\
\hline Dependent Variables & \\
\hline Log Birthweight & 0.020 \\
& $(0.024)$ \\
Very Low Birthweight & $-0.028^{* * *}$ \\
Low Birthweight & $(0.007)$ \\
& $-0.055^{* *}$ \\
High Birthweight & $(0.025)$ \\
& $-0.024^{* *}$ \\
1st Stage F-test & $(0.011)$ \\
& $\{127.320\}$ \\
\hline Log Gestational Age & {$[116,184]$} \\
Preterm<37 weeks & $0.016^{* * *}$ \\
& $(0.003)$ \\
1st Stage F-test & -0.020 \\
& $(0.014)$ \\
\hline Log Head Circumference & $\{223.940\}$ \\
& {$[961,594]$} \\
1st Stage F-test & 0.011 \\
& $(0.007)$ \\
\hline Any Child Died & $\{125.249\}$ \\
1st Stage F-test & {$[115,978]$} \\
\hline
\end{tabular}

The entries in parentheses are standard errors of the estimated coefficients, clustered at the birth year by province level. *,**, and *** indicate statistical significance at the $10 \%, 5 \%$, and $1 \%$ levels, respectively. All models include recentered birth date in months differentiated by exposure to the 1997 reform status, mother's month of birth dummies, and province fixed effects and province specific maternal birth month-year trends. Birth outcome models also control for child's birth year fixed effects and male child dummy. Birth outcome models are weighted by number of women in fertility age (ages 15 to 49 ) in the province. Survey weights provided by the PHC are used in mortality estimations. Number of observations are in square brackets []. ${ }^{\text {st }}$ Stage F-Statistics are provided in curly brackets \{\} . 
Table 8

Gender Specific IV Estimates of the Impact of Maternal Education on Child Health

\begin{tabular}{|c|c|c|}
\hline & $\begin{array}{c}\text { (1) } \\
\text { Daughter } \\
\text { Sample }\end{array}$ & $\begin{array}{c}(2) \\
\text { Son } \\
\text { Sample }\end{array}$ \\
\hline \multicolumn{3}{|c|}{ Panel A: Birth Outcomes } \\
\hline \multicolumn{3}{|l|}{ Dependent Variables } \\
\hline Log Birthweight & $\begin{array}{c}0.032 \\
(0.029)\end{array}$ & $\begin{array}{l}0.045^{*} \\
(0.026)\end{array}$ \\
\hline Very Low Birthweight & $\begin{array}{c}-0.060 * * * \\
(0.016)\end{array}$ & $\begin{array}{c}-0.032 * * * \\
(0.011)\end{array}$ \\
\hline Low Birthweight & $\begin{array}{l}-0.078 \\
(0.049)\end{array}$ & $\begin{array}{c}-0.070 * * * * \\
(0.026)\end{array}$ \\
\hline High Birthweight & $\begin{array}{c}-0.030 * * * \\
(0.01)\end{array}$ & $\begin{array}{c}-0.023 \\
(0.018)\end{array}$ \\
\hline 1st Stage F-test & $\begin{array}{l}\{74.157\} \\
{[90,985]}\end{array}$ & $\begin{array}{l}\{23.479\} \\
{[95,855]}\end{array}$ \\
\hline Log Gestational Age & $\begin{array}{c}0.024 * * * \\
(0.004)\end{array}$ & $\begin{array}{c}0.021 * * * \\
(0.005)\end{array}$ \\
\hline Preterm<37 weeks & $\begin{array}{c}-0.069 * * * \\
(0.024)\end{array}$ & $\begin{array}{c}-0.031^{*} \\
(0.018)\end{array}$ \\
\hline 1st Stage F-test & $\begin{array}{l}\{179.517\} \\
{[722,387]}\end{array}$ & $\begin{array}{l}\{113.265\} \\
{[763,966]}\end{array}$ \\
\hline Log Head Circumference & $\begin{array}{c}0.01 \\
(0.012)\end{array}$ & $\begin{array}{c}0.017 * * \\
(0.008)\end{array}$ \\
\hline 1st Stage F-test & $\begin{array}{l}\{75.606\} \\
{[90,801]}\end{array}$ & $\begin{array}{c}\{23.67 \\
{[95,704]} \\
\end{array}$ \\
\hline \multicolumn{3}{|c|}{ Panel B: Child Mortality } \\
\hline Any Child Died & $\begin{array}{c}-0.012 * \\
(0.007)\end{array}$ & $\begin{array}{c}-0.014 * \\
(0.007)\end{array}$ \\
\hline 1st Stage F-test & $\begin{array}{c}\{374.9\} \\
{[221,061]}\end{array}$ & $\begin{array}{c}\{374.9\} \\
{[236,081]}\end{array}$ \\
\hline
\end{tabular}

The entries in parentheses are standard errors of the estimated coefficients, clustered at the birth year by province level. *,**, and *** indicate statistical significance at the $10 \%, 5 \%$, and $1 \%$ levels, respectively. All models include re-centered birth date in months differentiated by exposure to the 1997 reform status, mother's month of birth dummies, and province fixed effects and province specific maternal birth month-year trends. Birth outcome models also control for child's birth year fixed effects and male child dummy. Birth outcome models are weighted by number of women in fertility age (ages 15 to 49) in the province. Survey weights provided by the PHC are used in mortality estimations. Number of observations are in square brackets []. $1^{\text {st }}$ Stage FStatistics are provided in curly brackets \{\} . 
Table 9

Two Sample Instrumental Variable Estimates

\begin{tabular}{cccccc}
\hline & $(1)$ & $(2)$ & $(3)$ & $(4)$ & $(5)$ \\
\hline & First Stage & First Stage & Reduced & 2 Sample IV & 2 Sample IV \\
& HLFS & PHC & Form & HLFS & PHC \\
\hline Dependent Variables & & & & \\
\hline Log Birthweight & $0.245^{* * *}$ & $0.227^{* * *}$ & $0.00287^{* *}$ & $0.0100^{*}$ & $0.013^{* *}$ \\
& $(0.015)$ & $(0.012)$ & $(0.00123)$ & $(0.005)$ & $(0.005)$ \\
Very Low Birthweight & $0.245^{* * *}$ & $0.227^{* * *}$ & $-0.00355^{* * *}$ & $-0.014^{* * *}$ & $-0.016^{* * *}$ \\
& $(0.015)$ & $(0.012)$ & $(0.00056)$ & $(0.002)$ & $(0.002)$ \\
Low Birthweight & $0.245^{* * *}$ & $0.227^{* * *}$ & $-0.00563^{* * *}$ & $-0.022^{* * *}$ & $-0.025^{* * *}$ \\
& $(0.015)$ & $(0.012)$ & $(0.00171)$ & $(0.007)$ & $(0.007)$ \\
High Birthweight & $0.245^{* * *}$ & $0.227^{* * *}$ & $-0.00200^{* * *}$ & $-0.008^{* * *}$ & $-0.009^{* * *}$ \\
& $(0.015)$ & $(0.012)$ & $(0.00073)$ & $(0.003)$ & $(0.003)$ \\
& {$[154,160]$} & {$[340,091]$} & {$[186,840]$} & {$[186,840]$} & {$[186,840]$} \\
\hline Log Gestational Age & $0.245^{* * *}$ & $0.227 * * *$ & $0.00190^{* * *}$ & $0.008^{* * *}$ & $0.008 * * *$ \\
& $(0.015)$ & $(0.012)$ & $(0.0002)$ & $(0.001)$ & $(0.001)$ \\
Preterm & $0.245^{* * *}$ & $0.227 * * *$ & $-0.00414 * * *$ & $-0.017 * * *$ & $-0.018^{* * *}$ \\
& $(0.015)$ & $(0.012)$ & $(0.00116)$ & $(0.005)$ & $(0.000)$ \\
& {$[154,160]$} & {$[340,091]$} & {$[1,486,353]$} & {$[1,486,353]$} & {$[1,486,353]$} \\
\hline Log Head Circumference & $0.245^{* * *}$ & $0.227 * * *$ & $0.00100^{*}$ & $0.00373 *$ & $0.00441^{*}$ \\
& $(0.015)$ & $(0.012)$ & $(0.00053)$ & $(0.00211)$ & $(0.00234)$ \\
& {$[154,160]$} & {$[340,091]$} & {$[186,505]$} & {$[186,505]$} & {$[186,505]$} \\
\hline
\end{tabular}

The entries in parentheses are standard errors of the estimated coefficients, clustered at the birth year by province level. *,**, and *** indicate statistical significance at the $10 \%, 5 \%$, and $1 \%$ levels, respectively. All models include re-centered birth date in months differentiated by exposure to the 1997 reform status, mother's month of birth dummies, child's birth year fixed effects, province fixed effects, and province specific maternal birth month-year trends. Birth outcome models are weighted by number of women in fertility age (ages 15 to 49 ) in the province. Survey weights provided by the PHC and HLFS are used in corresponding estimations. Column headings pertains to data used in estimations. Number of observations are in square brackets []. 


\section{Table 10}

Instrumental Variable Estimates of the Impact of Maternal Education on Maternal Behaviors

\begin{tabular}{|c|c|c|c|c|c|c|c|}
\hline & $(1)$ & $(2)$ & $(3)$ & $(4)$ & $(5)$ & $(6)$ & $(7)$ \\
\hline & OLS & IV & $\begin{array}{c}\text { Intent to } \\
\text { Treat Estimates }\end{array}$ & $\begin{array}{c}\text { First Stage } \\
\text { HLFS }\end{array}$ & $\begin{array}{c}\text { First Stage } \\
\text { PHC }\end{array}$ & $\begin{array}{c}2 \text { Sample IV } \\
\text { HLFS }\end{array}$ & $\begin{array}{c}2 \text { Sample IV } \\
\text { PHC }\end{array}$ \\
\hline \multicolumn{8}{|l|}{ Dependent Variables } \\
\hline Normal Birth & $\begin{array}{c}-0.11650 * * * \\
(0.00393)\end{array}$ & $\begin{array}{c}0.266 * * * \\
(0.039)\end{array}$ & $\begin{array}{c}0.02289 * * * \\
(0.00238)\end{array}$ & $\begin{array}{c}0.245 * * * \\
(0.015)\end{array}$ & $\begin{array}{c}0.227 * * * \\
(0.012)\end{array}$ & $\begin{array}{c}0.093 * * * \\
(0.014)\end{array}$ & $\begin{array}{c}0.100 * * * \\
(0.012)\end{array}$ \\
\hline 1st Stage F-test & {$[1,594,793]$} & $\begin{array}{c}\{167.822\} \\
{[1,594,793]}\end{array}$ & {$[1,594,793]$} & {$[154,160]$} & {$[340,091]$} & {$[1,594,793]$} & {$[1,594,793]$} \\
\hline Ever Smoked & $\begin{array}{c}0.01900 * * * \\
(0.0012)\end{array}$ & $\begin{array}{c}-0.084 * * * \\
(0.023)\end{array}$ & $\begin{array}{c}-0.00834 * * * \\
(0.00192)\end{array}$ & $\begin{array}{c}0.245 * * * \\
(0.015)\end{array}$ & $\begin{array}{c}0.227 * * * \\
(0.012)\end{array}$ & $\begin{array}{c}-0.034 * * * \\
(0.009)\end{array}$ & $\begin{array}{c}-0.037 * * * \\
(0.009)\end{array}$ \\
\hline Current Smoker & $\begin{array}{c}0.00863 * * * \\
(0.00137)\end{array}$ & $\begin{array}{c}-0.034 * * * \\
(0.013)\end{array}$ & $\begin{array}{c}-0.00341 * * * \\
(0.00122)\end{array}$ & $\begin{array}{c}0.245^{* * * *} \\
(0.015)\end{array}$ & $\begin{array}{c}0.227 * * * \\
(0.012)\end{array}$ & $\begin{array}{c}-0.014 * * * \\
(0.005)\end{array}$ & $\begin{array}{c}-0.015 * * * \\
(0.005)\end{array}$ \\
\hline 1st Stage F-test & {$[550,001]$} & $\begin{array}{l}\{222.429\} \\
{[550,001]}\end{array}$ & {$[550,001]$} & {$[154,160]$} & {$[340,091]$} & {$[550,001]$} & {$[550,001]$} \\
\hline
\end{tabular}

The entries in parentheses are standard errors of the estimated coefficients, clustered at the birth year by province level. *, **, and $* * *$ indicate statistical significance at the $10 \%, 5 \%$, and $1 \%$ levels, respectively. All models include re-centered birth date in months differentiated by exposure to the 1997 reform status, mother's month of birth dummies, and province fixed effects, province specific maternal birth month-year trends, child's birth year fixed effects, and male child dummy. Models are weighted by number of women in fertility age (ages 15 to 49 ) in the province. Number of observations are in square brackets []. $1^{\text {st }}$ Stage F-Statistics are provided in curly brackets \{\} . 


\section{Appendix Figure 1: Trends in Educational Attainment by Birth Cohort}
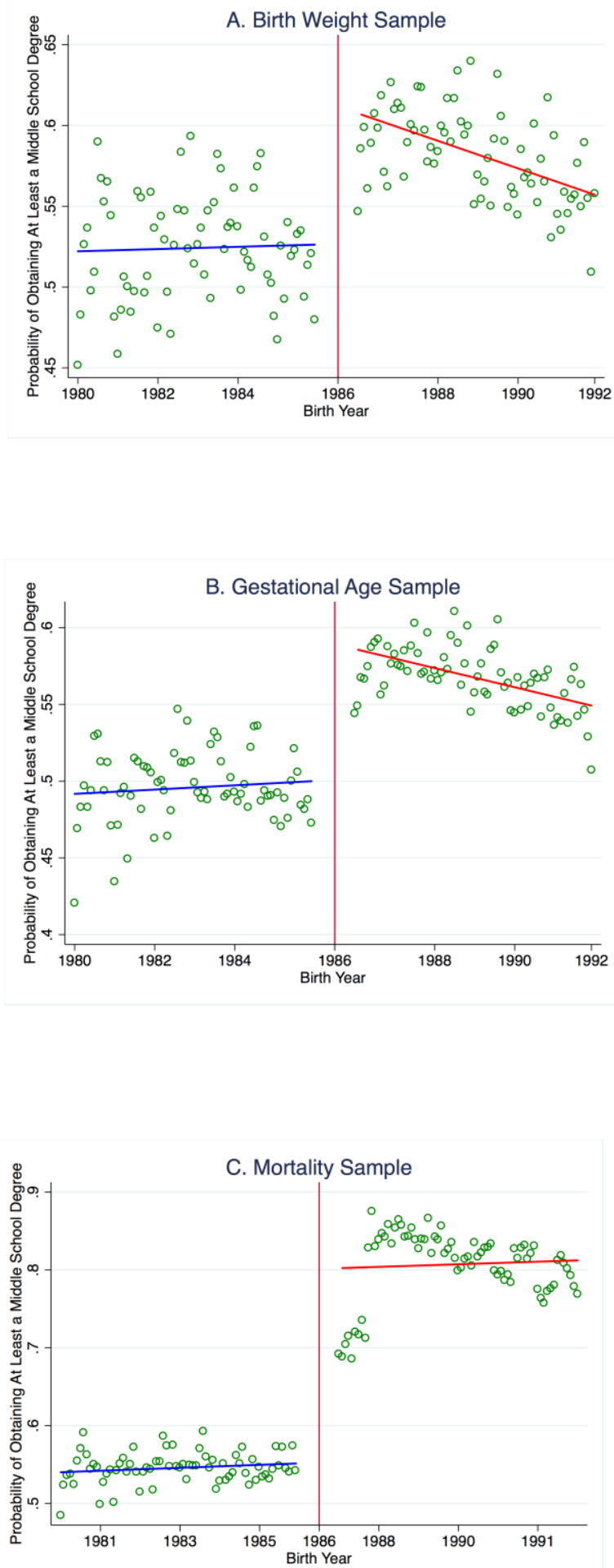


\section{Appendix Figure 2: Balanced Covariates}
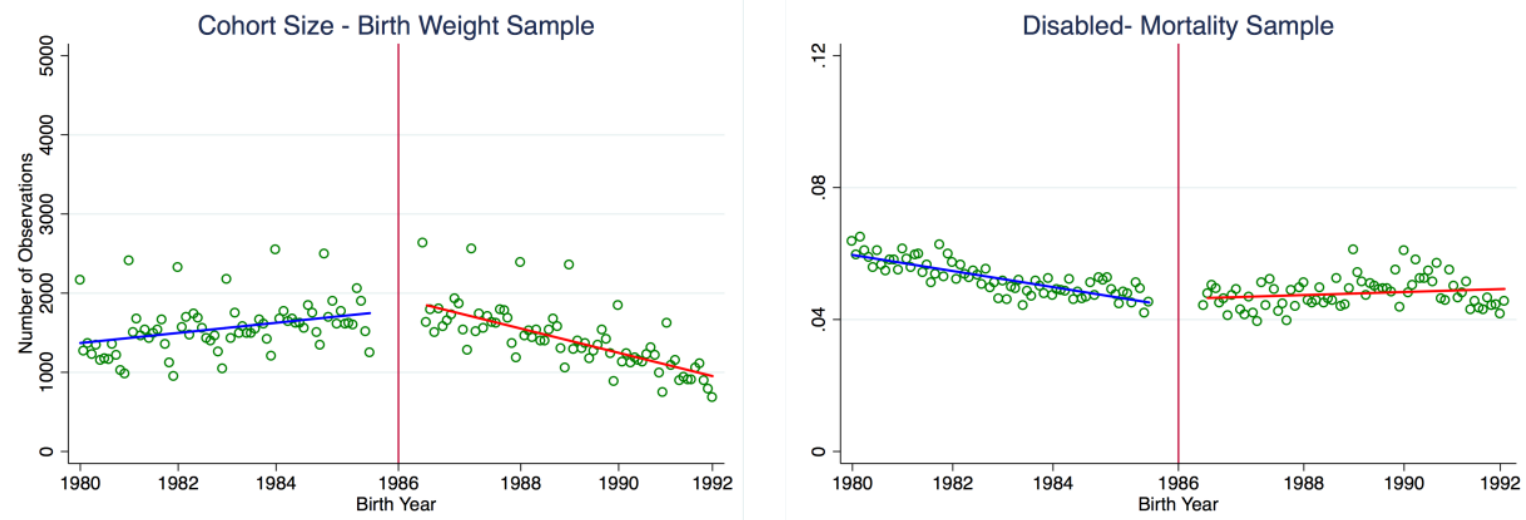

Appendix Figure 3: McCrary Test
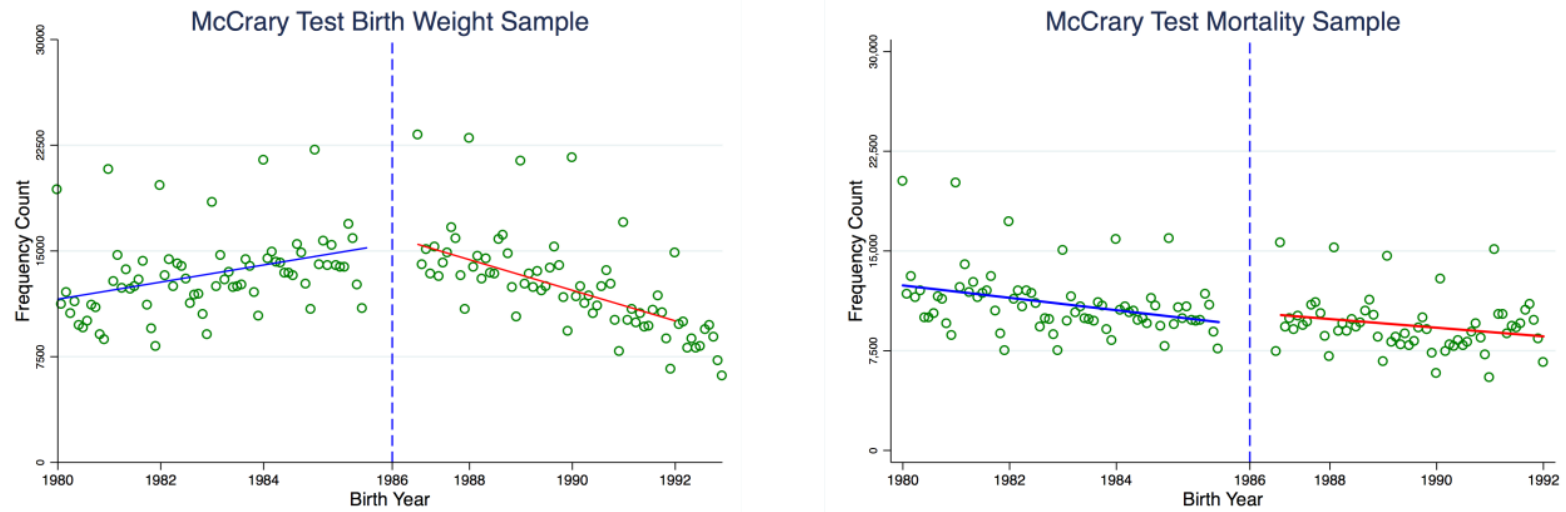
Appendix Table 1

Trends in the Number of Elementary, Middle, and Primary Schools in 1990s

\begin{tabular}{|c|c|c|c|}
\hline \multirow{3}{*}{$\begin{array}{c}\text { Academic } \\
\text { Year }\end{array}$} & \multicolumn{3}{|c|}{ Total Number of Schools } \\
\hline & Elementary & Middle & Primary \\
\hline & School & School & School \\
\hline $1991-92$ & 50,701 & 7,025 & $\mathrm{~N} / \mathrm{A}$ \\
\hline 1992-93 & 49,974 & 7,544 & N/A \\
\hline 1993-94 & 49,599 & 8,318 & N/A \\
\hline 1994-95 & 48,429 & 8,897 & N/A \\
\hline $1995-96$ & 49,240 & 9,385 & N/A \\
\hline $1996-97$ & 47,313 & 9,830 & N/A \\
\hline $1997-98$ & N/A & N/A & 46,801 \\
\hline 1998-99 & N/A & N/A & 44,433 \\
\hline 1999-00 & N/A & N/A & 32,634 \\
\hline $2000-01$ & N/A & N/A & 35,356 \\
\hline
\end{tabular}

The data come from the Ministry of National Education's 2000-01 Yearbook. 
Appendix Table 2

Main Reasons for Not Attending School Among Ever Married Women Who Were Not Bound by the 1997 Education Reform

\begin{tabular}{lccc}
\hline Reasons for Dropping Out School & Total & Urban & Rural \\
\hline School Not Accessible & 0.055 & 0.037 & 0.075 \\
Did not like school/ did not pass exams & 0.195 & 0.239 & 0.150 \\
Cannot afford schooling expenses & 0.056 & 0.074 & 0.036 \\
Had enough schooling & 0.007 & 0.006 & 0.007 \\
Needed to earn money & 0.014 & 0.021 & 0.006 \\
Family needed help & 0.016 & 0.012 & 0.020 \\
Take care of children & 0.001 & 0.001 & 0.001 \\
Got married & 0.021 & 0.023 & 0.020 \\
His/her family doesn't permit child to go to school & 0.401 & 0.362 & 0.446 \\
Other & 0.204 & 0.191 & 0.220 \\
Don't Know/ Missing & 0.023 & 0.017 & 0.028 \\
Number of Observations & 1,563 & 829 & 734 \\
\hline
\end{tabular}

The data come from the Ever-Married Module of the Turkish Demographic and Health Survey collected in 1998. The table shows the percentage distribution of women aged 15-24 who stopped attending school upon earning a 5-year elementary school diploma by reasons for not continuing their education. Women who were between 15 and 24 were not affected by the 1997 education reform. 
Appendix Table 3

Studies Using Natural Experiments to Estimate the Effect of Maternal Education on Child Health in Developing Countries

\begin{tabular}{|c|c|c|c|c|c|c|}
\hline Study & Country & Identification & $\begin{array}{c}\text { Outcomes Coinciding } \\
\text { With This Study }\end{array}$ & $\begin{array}{l}\text { Impact of Additional } \\
\text { Year of Schooling }\end{array}$ & $\begin{array}{c}\text { No. of } \\
\text { Observations }\end{array}$ & Notes \\
\hline $\begin{array}{l}\text { Breierova } \\
\text { and Duflo } \\
(2004)\end{array}$ & Indonesia & $\begin{array}{l}\text { Age and region specific exposure to the school } \\
\text { construction program (INPRES) that took } \\
\text { place between } 1973 \text { and } 1978 .\end{array}$ & $\begin{array}{l}\text { Total Number of } \\
\text { Children Died }\end{array}$ & $\begin{array}{l}45 \% \text { decrease } \\
\text { in the total number } \\
\text { of children died }\end{array}$ & 122,818 & First stage F-test statistic is $<5$ \\
\hline $\begin{array}{l}\text { Chou et al. } \\
(2010)\end{array}$ & Taiwan & $\begin{array}{l}\text { Age and region specific exposure to the } \\
\text { school construction program joint with } \\
\text { compulsory schooling reform in } 1968-69 \text {. }\end{array}$ & $\begin{array}{l}\text { Birth weight, } \\
\text { Child mortality }\end{array}$ & $\begin{array}{l}\text { Lowers the incidence } \\
\text { of low birth } \\
\text { weight by } 25 \% \text {. }\end{array}$ & $7,853 *$ & \\
\hline $\begin{array}{l}\text { Grépin and } \\
\text { Bharadwaj } \\
(2015)\end{array}$ & Zimbabwe & $\begin{array}{l}\text { Age specific exposure to education reform } \\
\text { followed by independence in } 1980 .\end{array}$ & Child mortality & $\begin{array}{l}\text { Lowers the } \\
\text { child mortality } \\
\text { by } 21 \% \text {. }\end{array}$ & $7813 * *$ & $\begin{array}{l}3339 \text { observations in treatment group; } \\
3103 \text { observations in control group. }\end{array}$ \\
\hline $\begin{array}{l}\text { Günes } \\
(2015)\end{array}$ & Turkey & $\begin{array}{l}\text { Age specific exposure to the } 1997 \text { education reform } \\
\text { and the intensity of the additional classrooms } \\
\text { constructed in mother's birth province due to the reform }\end{array}$ & $\begin{array}{l}\text { Birth weight, } \\
\text { height/weight for age } \\
\text { for age z-scores }\end{array}$ & $\begin{array}{l}\text { Decreases } \\
\text { very low birth } \\
\text { weight by } 85 \% \text {. }\end{array}$ & 1677 & $\begin{array}{l}265 \text { observations in the treatment group; } \\
1412 \text { observations in the control group. }\end{array}$ \\
\hline Keats (2014) & Uganda & $\begin{array}{l}\text { Exposure to a national reform that eliminates } \\
\text { primary school fees in } 1997\end{array}$ & $\begin{array}{l}\text { Preventative care } \\
\text { and chronic } \\
\text { malnutrition }\end{array}$ & $\begin{array}{l}\text { Null effect for mortality. } \\
\text { Decreases stunting by } \\
18 \% \text { and anemia by } 14 \% \text {. }\end{array}$ & 8,348 & \\
\hline $\begin{array}{l}\text { Makate and } \\
\text { Makate } \\
(2016)\end{array}$ & Malawi & $\begin{array}{l}\text { Elimination of schooling fees due to the } 1994 \\
\text { Universal Primary Schooling Program. }\end{array}$ & $\begin{array}{l}\text { Under } 5 \text { Mortality } \\
\text { Infant Mortality }\end{array}$ & $\begin{array}{l}\text { Lowers mortality by } \\
6.48 \% \text {. }\end{array}$ & 40,540 & \\
\hline $\begin{array}{l}\text { Zhang } \\
(2014)\end{array}$ & China & $\begin{array}{l}\text { Mothers' exposure to high school closures after } \\
\text { the Cultural Revolution }\end{array}$ & $\begin{array}{l}\text { Birth weight, } \\
\text { Child mortality }\end{array}$ & Null effect. & 22,444 & \\
\hline
\end{tabular}

* Chou et al. (2010) use data aggregated at the parental county of by birth year level.

** The number of mothers in the sample 
Appendix Table 4

The Impact of Being Exposed to the 1997 Education Reform on the Likelihood of Providing Missing Information on Outcome Measures and Maternal Education Panel A. Missing Birth weight and Mothers Education on Reform

$\begin{array}{ll}\text { Education Reform } & 0.000197\end{array}$

(0.00069)

$[2,943,692]$

Panel B. Missing Gestational Age and Mothers Education on Reform

$\begin{array}{ll}\text { Education Reform } & 0.001056\end{array}$

$(0.00125)$

$[2,943,692]$

Panel C. Missing Birth Method and Mothers Education on Reform

$\begin{array}{ll}\text { Education Reform } & 0.000066\end{array}$

$(0.001325)$

$[2,943,692]$

Education Reform

Panel D. Missing Smoking Behavior and Mothers Education on Reform

$-0.001275$

$(0.00148)$

$[2,943,692]$

The entries in parentheses are standard errors of the estimated coefficients, clustered at the birth year by province level. *, **, and $* * *$ indicate statistical significance at the $10 \%, 5 \%$, and $1 \%$ levels, respectively. All models include re-centered birth month differentiated by exposure to the 1997 reform status, mother's month of birth dummies, province fixed effects, child's birth year fixed effects, and male child dummy. Models are weighted by number of women in fertility age (ages 15 to 49) in the province. Number of observations are in square brackets []. 
Appendix Table 5

Instrumental Variable Estimates with Alternative Cluster Levels

\begin{tabular}{|c|c|c|c|c|c|c|}
\hline & $\begin{array}{c}(1) \\
\text { Cluster by } \\
\text { Province } \\
\text { Level } \\
\end{array}$ & $\begin{array}{c}\text { (2) } \\
\text { Cluster by } \\
\text { Birth } \\
\text { Month Level } \\
\end{array}$ & $\begin{array}{c}\text { (3) } \\
\text { Cluster by } \\
\text { Birth Month } \\
\text { by Province }\end{array}$ & $\begin{array}{c}\text { (4) } \\
\text { Cluster by } \\
\text { Birth Year } \\
\text { by NUTS1 }\end{array}$ & $\begin{array}{c}(5) \\
\text { Cluster by } \\
\text { Birth Year } \\
\text { Level } \\
\end{array}$ & $\begin{array}{c}(6) \\
\text { Wild } \\
\text { Bootstrap } \\
\text { P-Values } \\
\end{array}$ \\
\hline \multicolumn{7}{|c|}{ Panel A: Birth Outcomes } \\
\hline \multicolumn{7}{|l|}{ Dependent Variables } \\
\hline Log Birthweight & $\begin{array}{c}0.038^{* * * *} \\
(0.008)\end{array}$ & $\begin{array}{c}0.038 \\
(0.032)\end{array}$ & $\begin{array}{l}0.038 \\
(0.03)\end{array}$ & $\begin{array}{c}0.038 * * \\
(0.019)\end{array}$ & $\begin{array}{c}0.038 * * \\
(0.015)\end{array}$ & 0.040 \\
\hline Very Low Birthweight & $\begin{array}{c}-0.047 * * * \\
(0.011)\end{array}$ & $\begin{array}{c}-0.047 * * * \\
(0.016)\end{array}$ & $\begin{array}{c}-0.047 * * * \\
(0.016)\end{array}$ & $\begin{array}{c}-0.047 * * * \\
(0.012)\end{array}$ & $\begin{array}{c}-0.047 * * * \\
(0.012)\end{array}$ & 0.015 \\
\hline Low Birthweight & $\begin{array}{c}-0.074 * * \\
(0.035)\end{array}$ & $\begin{array}{c}-0.074 * \\
(0.043)\end{array}$ & $\begin{array}{c}-0.074^{*} \\
(0.044)\end{array}$ & $\begin{array}{c}-0.074 * * \\
(0.029)\end{array}$ & $\begin{array}{c}-0.074 * * * \\
(0.027)\end{array}$ & 0.005 \\
\hline High Birthweight & $\begin{array}{c}-0.026^{*} \\
(0.016)\end{array}$ & $\begin{array}{c}-0.026 * * \\
(0.011)\end{array}$ & $\begin{array}{c}-0.026 * * \\
(0.013)\end{array}$ & $\begin{array}{c}-0.026 * * * \\
(0.010)\end{array}$ & $\begin{array}{c}-0.026 * * * \\
(0.007)\end{array}$ & 0.055 \\
\hline 1st Stage F-test & $\begin{array}{c}\{31.689\} \\
{[186,840]}\end{array}$ & $\begin{array}{c}\{81.28\} \\
{[186,840]}\end{array}$ & $\begin{array}{l}\{101.742\} \\
{[186,840]}\end{array}$ & $\begin{array}{c}\{53.474\} \\
{[186,840]}\end{array}$ & $\begin{array}{c}\{26.857\} \\
{[186,840]}\end{array}$ & \\
\hline Log Gestational Age & $\begin{array}{c}0.023 * * * \\
(0.006)\end{array}$ & $\begin{array}{c}0.023 * * * \\
(0.003)\end{array}$ & $\begin{array}{c}0.023 * * * \\
(0.004)\end{array}$ & $\begin{array}{c}0.023 * * * \\
(0.004)\end{array}$ & $\begin{array}{c}0.023 * * * \\
(0.003)\end{array}$ & 0.005 \\
\hline Preterm<37 weeks & $\begin{array}{c}-0.050^{* * * *} \\
(0.018)\end{array}$ & $\begin{array}{c}-0.050^{* * * *} \\
(0.018)\end{array}$ & $\begin{array}{c}-0.050 * * * \\
(0.019)\end{array}$ & $\begin{array}{c}-0.050 * * * \\
(0.014)\end{array}$ & $\begin{array}{c}-0.050^{* * *} \\
(0.013)\end{array}$ & 0.020 \\
\hline 1st Stage F-test & $\begin{array}{c}\{73.456\} \\
{[1,486,353} \\
\end{array}$ & $\begin{array}{c}\{314.821\} \\
{[1,486,353]}\end{array}$ & $\begin{array}{c}\{441.995\} \\
{[1,486,353]}\end{array}$ & $\begin{array}{c}\{127.103\} \\
{[1,486,353]}\end{array}$ & $\begin{array}{c}\{65.52\} \\
{[1,486,353]}\end{array}$ & \\
\hline Log Head Circumference & $\begin{array}{c}0.013 \\
(0.009)\end{array}$ & $\begin{array}{l}0.013 \\
(0.01)\end{array}$ & $\begin{array}{l}0.013 \\
(0.01)\end{array}$ & $\begin{array}{l}0.013 * \\
(0.008)\end{array}$ & $\begin{array}{c}0.013^{* *} \\
(0.007)\end{array}$ & 0.141 \\
\hline 1st Stage F-test & $\begin{array}{c}\{31.953\} \\
{[186,505]} \\
\end{array}$ & $\begin{array}{c}\{81.238\} \\
{[186,505]} \\
\end{array}$ & $\begin{array}{l}\{101.947\} \\
{[186,505]} \\
\end{array}$ & $\begin{array}{c}\{54.068\} \\
{[186,505]}\end{array}$ & $\begin{array}{c}\{27.103\} \\
{[186,505]} \\
\end{array}$ & \\
\hline Any Child Died & $\begin{array}{c}-0.018 * * \\
(0.008) \\
\{205.309\} \\
{[340,091]}\end{array}$ & $\begin{array}{c}-0.018 * * * \\
(0.006) \\
\{374.9\} \\
{[340,091]}\end{array}$ & N/A & N/A & N/A & N/A \\
\hline
\end{tabular}

The entries in parentheses are standard errors of the estimated coefficients, clustered at the birth year by province level. *, **, and *** indicate statistical significance at the 10\%,5\%, and $1 \%$ levels, respectively. All models include re-centered birth date in months differentiated by exposure to the 1997 reform status, mother's month of birth dummies, province fixed effects, and province specific maternal birth month-year trends. Birth outcome models also control for child's birth year fixed effects and male child dummy. Birth outcome models are weighted by number of women in fertility age (ages 15 to 49) in the province. Survey weights provided by the PHC are used in mortality estimations. Number of observations are in square brackets []. $1^{\text {st }}$ Stage F-Statistics are provided in curly brackets \{\} . 


\begin{tabular}{|c|c|c|c|c|c|}
\hline \multicolumn{6}{|c|}{$\begin{array}{c}\text { Appendix Table } 6 \\
\text { Instrumental Variable Estimates of the Impact of Maternal Education on Child Health } \\
\text { Using the Turkish Demographic and Health Surveys }\end{array}$} \\
\hline & $(1)$ & $(2)$ & $(3)$ & $(4)$ & $(5)$ \\
\hline & $80-92$ & $81-91$ & $82-90$ & $83-89$ & $76-96$ \\
\hline \multicolumn{6}{|c|}{ Panel A: Birth Outcomes } \\
\hline \multicolumn{6}{|l|}{ Dependent Variables } \\
\hline Log Birthweight & $\begin{array}{l}-0.068 \\
(0.136)\end{array}$ & $\begin{array}{l}-0.012 \\
(0.13)\end{array}$ & $\begin{array}{l}-0.025 \\
(0.148)\end{array}$ & $\begin{array}{l}-0.173 \\
(0.306)\end{array}$ & $\begin{array}{c}0.089 \\
(0.124)\end{array}$ \\
\hline Very Low Birthweight & $\begin{array}{c}0.033 \\
(0.051)\end{array}$ & $\begin{array}{c}-0.023 \\
(0.046)\end{array}$ & $\begin{array}{l}-0.011 \\
(0.049)\end{array}$ & $\begin{array}{c}0.198 \\
(0.164)\end{array}$ & $\begin{array}{l}-0.004 \\
(0.052)\end{array}$ \\
\hline Low Birthweight & $\begin{array}{c}0.116 \\
(0.196)\end{array}$ & $\begin{array}{c}0.068 \\
(0.192)\end{array}$ & $\begin{array}{c}0.141 \\
(0.222)\end{array}$ & $\begin{array}{c}0.084 \\
(0.447)\end{array}$ & $\begin{array}{c}-0.012 \\
(0.165)\end{array}$ \\
\hline High Birthweight & $\begin{array}{l}-0.035 \\
(0.067)\end{array}$ & $\begin{array}{l}-0.044 \\
(0.066)\end{array}$ & $\begin{array}{l}-0.04 \\
(0.08)\end{array}$ & $\begin{array}{l}-0.015 \\
(0.152)\end{array}$ & $\begin{array}{l}-0.014 \\
(0.054)\end{array}$ \\
\hline 1st Stage F-test & $\begin{array}{c}\{13.432\} \\
{[3,365]}\end{array}$ & $\begin{array}{c}\{13.884\} \\
{[2,808]}\end{array}$ & $\begin{array}{c}\{10.053\} \\
{[2,211]}\end{array}$ & $\begin{array}{l}\{2.637\} \\
{[1,702]}\end{array}$ & $\begin{array}{c}\{17.665\} \\
{[5,111]}\end{array}$ \\
\hline Current Smoker & $\begin{array}{c}-0.173 \\
(0.163)\end{array}$ & $\begin{array}{c}-0.114 \\
(0.159)\end{array}$ & $\begin{array}{l}-0.274 \\
(0.196)\end{array}$ & $\begin{array}{l}-0.214 \\
(0.28)\end{array}$ & $\begin{array}{l}-0.117 \\
(0.093)\end{array}$ \\
\hline 1st Stage F-test & $\begin{array}{c}\{42.531\} \\
{[6,564]} \\
\end{array}$ & $\begin{array}{c}\{44.738\} \\
{[5,391]} \\
\end{array}$ & $\begin{array}{c}\{36.788\} \\
{[4,229]} \\
\end{array}$ & $\begin{array}{c}\{21.549\} \\
{[3,144]} \\
\end{array}$ & $\begin{array}{l}\{87.729\} \\
{[11,175]}\end{array}$ \\
\hline \multicolumn{6}{|c|}{ Panel B: Child Mortality } \\
\hline Any Child Died & $\begin{array}{c}0.026 \\
(0.081)\end{array}$ & $\begin{array}{c}-0.051 \\
(0.079)\end{array}$ & $\begin{array}{c}-0.14 \\
(0.095)\end{array}$ & $\begin{array}{l}-0.370^{*} \\
(0.205)\end{array}$ & $\begin{array}{l}-0.024 \\
(0.071)\end{array}$ \\
\hline 1st Stage F-test & $\begin{array}{c}\{16.133\} \\
{[4,692]} \\
\end{array}$ & $\begin{array}{c}\{15.642\} \\
{[3,837]}\end{array}$ & $\begin{array}{c}\{12.543\} \\
{[2,976]}\end{array}$ & $\begin{array}{l}\{5.071\} \\
{[2,207]}\end{array}$ & $\begin{array}{c}\{20.974\} \\
{[7,930]} \\
\end{array}$ \\
\hline
\end{tabular}

These models estimated using data are from all available rounds of the Turkish Demographic Health Surveys collected in 2003, 2008, and 2013. The entries in parentheses are standard errors of the estimated coefficients, clustered at the birth year by province level. $* * *$, and $* * *$ indicate statistical significance at the $10 \%, 5 \%$, and $1 \%$ levels, respectively. All models include re-centered birth-date in months differentiated by exposure to the 1997 reform status, mother's month of birth dummies, and province fixed effects and province specific maternal birth month-year trends. Survey weights provided by the DHS are used in estimations. Column headings pertains to data estimation intervals based on year of birth year of the mother. Number of observations are in square brackets []. ${ }^{\text {st }}$ Stage F-Statistics are provided in curly brackets \{\} . 
Appendix Table 7

Instrumental Variable Estimates

Assigning Alternative Probabilities to the Likelihood of Earning At least a Middle School Diploma Among Those Who Were Bound by the Reform but Reported Their Highest Level of Educational Attainment as Elementary School Diploma in the MHBOD

(1) (2) (3) (4)

Assigned Probability of Obtaining At Least a Middle School Degree Among Individuals

Who Were Bound by the Reform but Reported Their Highest Level of Educational Attainment as Elementary School Diploma (i.e., 5-Years of Basic Education)

\begin{tabular}{|c|c|c|c|c|}
\hline \multirow[b]{2}{*}{ Dependent Variables } & & & & \\
\hline & $(\mathrm{P})=1$ & $(\mathrm{P})=0.75$ & $(\mathrm{P})=0.50$ & $(\mathrm{P})=0.25$ \\
\hline \multirow[t]{2}{*}{ Log Birthweight } & $0.010 * *$ & $0.012 * *$ & $0.015 * *$ & $0.022 * *$ \\
\hline & $(0.004)$ & $(0.005)$ & $(0.007)$ & $(0.010)$ \\
\hline \multirow[t]{2}{*}{ Very Low Birthweight } & $-0.012 * * *$ & $-0.014 * * *$ & $-0.019 * * *$ & $-0.027 * * *$ \\
\hline & $(0.002)$ & $(0.003)$ & $(0.003)$ & $(0.005)$ \\
\hline \multirow[t]{2}{*}{ Low Birthweight } & $-0.019 * * *$ & $-0.023 * * *$ & $-0.030 * * *$ & $-0.043 * * *$ \\
\hline & $(0.006)$ & $(0.008)$ & $(0.010)$ & $(0.015)$ \\
\hline \multirow[t]{2}{*}{ High Birthweight } & $-0.007 * * *$ & $-0.008 * * *$ & $-0.011 * * *$ & $-0.015 * * *$ \\
\hline & $(0.002)$ & $(0.003)$ & $(0.004)$ & $(0.006)$ \\
\hline \multirow[t]{2}{*}{ 1st Stage Estimates } & $0.302 * * *$ & $0.245 * * *$ & $0.189 * * *$ & $0.132 * * *$ \\
\hline & $(0.01005)$ & $(0.00973)$ & $(0.00960)$ & $(0.00964)$ \\
\hline \multirow[t]{2}{*}{ 1st Stage F-test } & $\{899.901\}$ & $\{633.945\}$ & $\{386.378\}$ & $\{187.712\}$ \\
\hline & {$[186,840]$} & {$[186,840]$} & {$[186,840]$} & {$[186,840]$} \\
\hline \multirow[t]{2}{*}{ Log Gestational Age } & $0.007 * * *$ & $0.008 * * *$ & $0.010 * * *$ & $0.014 * * *$ \\
\hline & $(0.001)$ & $(0.001)$ & $(0.001)$ & $(0.002)$ \\
\hline \multirow[t]{2}{*}{ Preterm<37 weeks } & $-0.015 * * *$ & $-0.018 * * *$ & $-0.023 * * *$ & $-0.031 * * *$ \\
\hline & $(0.004)$ & $(0.005)$ & $(0.006)$ & $(0.009)$ \\
\hline \multirow[t]{2}{*}{ 1st Stage Estimates } & $0.283 * * *$ & $0.233 * * *$ & $0.183 * * *$ & $0.133 * * *$ \\
\hline & $(0.008)$ & $(0.008)$ & $(0.007)$ & $(0.007)$ \\
\hline \multirow[t]{2}{*}{ 1st Stage F-test } & $\{1175.917\}$ & $\{912.288\}$ & $\{630.541\}$ & $\{361.894\}$ \\
\hline & {$[1,486,353]$} & {$[1,486,353]$} & {$[1,486,353]$} & {$[1,486,353]$} \\
\hline \multirow[t]{2}{*}{ Log Head Circumference } & $0.003^{*}$ & $0.004 *$ & $0.005^{*}$ & $0.008 *$ \\
\hline & $(0.002)$ & $(0.002)$ & $(0.003)$ & $(0.004)$ \\
\hline \multirow[t]{2}{*}{ 1st Stage Estimates } & $0.302 * * *$ & $0.246 * * *$ & $0.189 * * *$ & $0.132 * * *$ \\
\hline & $(0.010)$ & $(0.009)$ & $(0.009)$ & $(0.009)$ \\
\hline \multirow[t]{2}{*}{ 1st Stage F-test } & $\{909.440\}$ & $\{640.618\}$ & $\{390.408\}$ & $\{189.704\}$ \\
\hline & {$[186,505]$} & {$[186,505]$} & {$[186,505]$} & {$[186,505]$} \\
\hline
\end{tabular}

The entries in parentheses are standard errors of the estimated coefficients, clustered at the birth year by province level. *,**, and $* * *$ indicate statistical significance at the $10 \%, 5 \%$, and $1 \%$ levels, respectively. All models include re-centered birth date in months differentiated by exposure to the 1997 reform status, mother's month of birth dummies, and province fixed effects, province specific maternal birth month-year trends, child's birth year fixed effects, and male child dummy. Birth outcome models are weighted by number of women in fertility age (ages 15 to 49 ) in the province. Number of observations are in square brackets []. $1^{\text {st }}$ Stage F-Statistics are provided in curly brackets \{\} . 
Appendix Table 8

Summary Statistics for Maternal Behaviors

\begin{tabular}{lccc}
\hline & All & Control & Treatment \\
\hline Normal Birth & 0.4644 & 0.4166 & 0.5174 \\
& $(0.4987)$ & $(0.493)$ & $(0.4997)$ \\
& {$[1,594,793]$} & {$[812,985]$} & {$[781,808]$} \\
\hline Ever Smoked & 0.1025 & 0.1203 & 0.0823 \\
& $(0.3032)$ & $(0.3253)$ & $(0.2748)$ \\
Current Smoker & 0.0683 & 0.0792 & 0.056 \\
& $(0.2522)$ & $(0.27)$ & $(0.2299)$ \\
& {$[550,001]$} & {$[281,422]$} & {$[268,579]$} \\
\hline
\end{tabular}

The means are generated using data from the Ministry of Health Birth Outcomes Data (MHBOD). Individuals born between 1987 and 1991 constitute the treatment group and those who were born between 1981 and 1985 form the control group. Standard deviations are in parentheses. Variables in Panel A are weighted by number of women in fertility age (ages 15 to 49 ) in the province. Number of observations are in square brackets []. 


\section{Appendix Table 9}

The Impact of Maternal Education on Maternal Behaviors, Robustness Checks

\begin{tabular}{|c|c|c|c|c|c|c|}
\hline & $\begin{array}{c}\text { (1) } \\
\text { Baseline } \\
\text { Estimates }\end{array}$ & $\begin{array}{c}\text { (2) } \\
\text { Intent to } \\
\text { Treat } \\
\text { Estimates }\end{array}$ & $\begin{array}{c}(3) \\
\text { Alt. Treatment } \\
\text { for 1986 Birth } \\
\text { Cohort } \mathrm{T}==0.25\end{array}$ & $\begin{array}{c}\text { (4) } \\
\text { Quadratic BC } \\
\text { Control } \\
\text { Function }\end{array}$ & $\begin{array}{c}(5) \\
\text { Local Linear IV } \\
\text { with rdrobust } \\
\text { command }\end{array}$ & $\begin{array}{c}(6) \\
\text { With Province } \\
\text { Specific Birth } \\
\text { Cohort Trends }\end{array}$ \\
\hline \multicolumn{7}{|l|}{ Dependent Variables } \\
\hline Normal Birth & $\begin{array}{c}0.269 * * * \\
(0.063)\end{array}$ & $\begin{array}{c}0.02289 * * * \\
(0.00238)\end{array}$ & $\begin{array}{c}0.214 * * * \\
(0.058)\end{array}$ & $\begin{array}{c}0.262 * * * \\
(0.058)\end{array}$ & $\begin{array}{c}0.237 * * * \\
(0.044)\end{array}$ & $\begin{array}{c}0.266 * * * \\
(0.039)\end{array}$ \\
\hline 1st Stage F-test & $\begin{array}{c}\{76.495\} \\
{[1,594,793]}\end{array}$ & $\begin{array}{c}--- \\
{[1,594,793]}\end{array}$ & $\begin{array}{c}\{80.488\} \\
{[1,775,812]}\end{array}$ & $\begin{array}{c}\{75.112\} \\
{[1,594,793]}\end{array}$ & {$[1,594,793]$} & $\begin{array}{c}\{167.822\} \\
{[1,594,793]}\end{array}$ \\
\hline Ever Smoked & $\begin{array}{c}-0.084 * * * \\
(0.026)\end{array}$ & $\begin{array}{c}-0.00834 * * * \\
(0.00192)\end{array}$ & $\begin{array}{c}-0.068 * * \\
(0.028)\end{array}$ & $\begin{array}{c}-0.083 * * * \\
(0.024)\end{array}$ & $\begin{array}{c}-0.067 * * \\
(0.028)\end{array}$ & $\begin{array}{c}-0.084 * * * \\
(0.023)\end{array}$ \\
\hline Current Smoker & $\begin{array}{c}-0.034 * * * \\
(0.013)\end{array}$ & $\begin{array}{c}-0.00341 * * * \\
(0.00122)\end{array}$ & $\begin{array}{c}-0.030 * * \\
(0.014)\end{array}$ & $\begin{array}{c}-0.034 * * * \\
(0.012)\end{array}$ & $\begin{array}{c}-0.029 * * \\
(0.013)\end{array}$ & $\begin{array}{c}-0.034 * * * \\
(0.013)\end{array}$ \\
\hline 1st Stage F-test & $\begin{array}{c}\{98.002\} \\
{[550,001]}\end{array}$ & $\begin{array}{c}--- \\
{[550,001]}\end{array}$ & $\begin{array}{l}\{107.353\} \\
{[612,733]}\end{array}$ & $\begin{array}{c}\{99.921\} \\
{[550,001]}\end{array}$ & {$[550,001]$} & $\begin{array}{l}\{222.429\} \\
{[550,001]}\end{array}$ \\
\hline
\end{tabular}

The entries in parentheses are standard errors of the estimated coefficients, clustered at the birth year by province level. *,**, and $* * *$ indicate statistical significance at the $10 \%, 5 \%$, and $1 \%$ levels, respectively. All models include re-centered birth date in months differentiated by exposure to the 1997 reform status, mother's month of birth dummies, province fixed effects, child's birth year fixed effects, and male child dummy. Birth outcome models are weighted by number of women in fertility age (ages 15 to 49 ) in the province. Number of observations are in square brackets []. $1^{\text {st }}$ Stage F-Statistics are provided in curly brackets \{\} . 


\section{Appendix Table 10 \\ Robustness of the IV Estimates of the Impact of Maternal Education on Maternal Behaviors to Using Alternative Bandwidths}

\begin{tabular}{ccccc}
\hline & $(1)$ & $(2)$ & $(3)$ & $(4)$ \\
& $80-92$ & $81-91$ & $82-90$ & $83-89$ \\
\hline Dependent Variables & & & & \\
\hline Normal Birth & $0.242^{* * *}$ & $0.266^{* * *}$ & $0.245^{* * *}$ & $0.208^{* * *}$ \\
& $(0.043)$ & $(0.039)$ & $(0.031)$ & $(0.023)$ \\
1st Stage F-test & $\{175.861\}$ & $\{167.822\}$ & $\{221.386\}$ & $\{319.168\}$ \\
& {$[1,834,716]$} & {$[1,594,793]$} & {$[1,316,711]$} & {$[1,017,506]$} \\
\hline Ever Smoked & $-0.083 * * *$ & $-0.084 * * *$ & $-0.057 * * *$ & $-0.056^{* *}$ \\
& $(0.018)$ & $(0.023)$ & $(0.022)$ & $(0.026)$ \\
Current Smoker & $-0.049 * * *$ & $-0.034 * * *$ & -0.019 & $-0.030^{* * *}$ \\
& $(0.012)$ & $(0.013)$ & $(0.012)$ & $(0.012)$ \\
1st Stage F-test & $\{231.656\}$ & $\{222.429\}$ & $\{228.806\}$ & $\{251.143\}$ \\
& {$[631,108]$} & {$[550,001]$} & {$[455,856]$} & {$[353,401]$} \\
\hline
\end{tabular}

The entries in parentheses are standard errors of the estimated coefficients, clustered at the birth year by province level. *,**, and *** indicate statistical significance at the $10 \%, 5 \%$, and $1 \%$ levels, respectively. All models include re-centered birth date in months differentiated by exposure to the 1997 reform status, mother's month of birth dummies, and province fixed effects, province specific maternal birth month-year trends, child's birth year fixed effects, and male child dummy. Models are weighted by number of women in fertility age (ages 15 to 49) in the province. Column headings pertain to data estimation intervals based on year of birth year of the mother. Number of observations are in square brackets []. ${ }^{\text {st }}$ Stage F-Statistics are provided in curly brackets \{\} . 
Appendix Table 11

Instrumental Variable Estimates with Alternative Cluster Levels- Maternal Behaviors

\begin{tabular}{|c|c|c|c|c|c|c|c|}
\hline & $\begin{array}{c}\text { (1) } \\
\text { Cluster by } \\
\text { Province } \\
\text { Level }\end{array}$ & $\begin{array}{c}\text { (2) } \\
\text { Cluster by } \\
\text { Birth } \\
\text { Month Level }\end{array}$ & $\begin{array}{c}\text { (3) } \\
\text { Cluster by } \\
\text { Birth Month } \\
\text { by Province }\end{array}$ & $\begin{array}{c}\text { (4) } \\
\text { Cluster by } \\
\text { Birth Year } \\
\text { by NUTS1 }\end{array}$ & $\begin{array}{c}\text { (5) } \\
\text { Cluster by } \\
\text { Birth Year } \\
\text { by NUTS2 }\end{array}$ & $\begin{array}{c}\text { (6) } \\
\text { Cluster by } \\
\text { Birth Year } \\
\text { Level }\end{array}$ & $\begin{array}{c}(7) \\
\text { Wild } \\
\text { Bootstrap } \\
\text { P-Values } \\
\end{array}$ \\
\hline \multicolumn{8}{|c|}{ Dependent Variables } \\
\hline Normal Birth & $\begin{array}{c}0.266 * * * \\
(0.045)\end{array}$ & $\begin{array}{c}0.266 * * * \\
(0.041)\end{array}$ & $\begin{array}{c}0.266 * * * \\
(0.039)\end{array}$ & $\begin{array}{c}0.266 * * * \\
(0.041)\end{array}$ & $\begin{array}{c}0.266^{* * * *} \\
(0.039)\end{array}$ & $\begin{array}{c}0.266 * * * \\
(0.058)\end{array}$ & 0.000 \\
\hline 1st Stage F-test & $\begin{array}{c}\{68.826\} \\
{[1,594,793]}\end{array}$ & $\begin{array}{c}\{351.223\} \\
{[1,594,793]}\end{array}$ & $\begin{array}{c}\{488.548\} \\
{[1,594,793]}\end{array}$ & $\begin{array}{c}\{140.562\} \\
{[1,594,793]}\end{array}$ & $\begin{array}{c}\{162.72\} \\
{[1,594,793}\end{array}$ & $\begin{array}{c}\{77.787\} \\
{[1,594,793]}\end{array}$ & \\
\hline Ever Smoked & $\begin{array}{c}-0.084 * * * \\
(0.023)\end{array}$ & $\begin{array}{c}-0.084 * * * \\
(0.027)\end{array}$ & $\begin{array}{c}-0.084 * * * \\
(0.03)\end{array}$ & $\begin{array}{c}-0.084 * * * \\
(0.024)\end{array}$ & $\begin{array}{c}-0.084 * * * \\
(0.023)\end{array}$ & $\begin{array}{c}-0.084 * * * \\
(0.02)\end{array}$ & 0.005 \\
\hline Current Smoker & $\begin{array}{c}-0.034 * * * \\
(0.007)\end{array}$ & $\begin{array}{c}-0.034 * \\
(0.02)\end{array}$ & $\begin{array}{c}-0.034 * \\
(0.02)\end{array}$ & $\begin{array}{c}-0.034 * * \\
(0.014)\end{array}$ & $\begin{array}{c}-0.034 * * * \\
(0.013)\end{array}$ & $\begin{array}{c}-0.034 * * * \\
(0.012)\end{array}$ & 0.090 \\
\hline 1st Stage F-test & $\begin{array}{c}\{56.732\} \\
{[550,001]}\end{array}$ & $\begin{array}{l}\{281.553\} \\
{[550,001]}\end{array}$ & $\begin{array}{l}\{329.173\} \\
{[550,001]}\end{array}$ & $\begin{array}{l}\{188.578\} \\
{[550,001]}\end{array}$ & $\begin{array}{l}\{218.393\} \\
{[550,001]}\end{array}$ & $\begin{array}{c}\{147.67\} \\
{[550,001]}\end{array}$ & \\
\hline
\end{tabular}

The entries in parentheses are standard errors of the estimated coefficients. *, **, and *** indicate statistical significance at the $10 \%, 5 \%$, and $1 \%$ levels, respectively. All models include re-centered birth date in months differentiated by exposure to the 1997 reform status, mother's month of birth dummies, province fixed effects, province specific maternal birth month-year trends, child's birth year fixed effects, and male child dummy. Models are weighted by number of women in fertility age (ages 15 to 49 ) in the province. Column headings pertain to alternative cluster levels. Number of observations are in square brackets []. $1^{\text {st }}$ Stage F-Statistics are provided in curly brackets \{\} . 